\title{
Review on experimental study and clinical application of low- intensity pulsed ultrasound in inflammation
}

\author{
Maosheng Xu, Liang Wang, Senmin Wu, Yanyan Dong, Xiu Chen, Shijia Wang, Xiuyun Li, \\ Chunpeng Zou \\ Department of Ultrasonography, The Second Affiliated Hospital and Yuying Children's Hospital of Wenzhou Medical University, Wenzhou, China \\ Correspondence to: Chunpeng Zou. The Second Affiliated Hospital and Yuying Children's Hospital of Wenzhou Medical University, 109 Xueyuan \\ Road, Lucheng District, Wenzhou 325027, Zhejiang, China. Email:chpzou@126.com.
}

\begin{abstract}
Low-intensity pulsed ultrasound (LIPUS), as physical therapy, is widely used in both research and clinical settings. It induces multiple bioeffects, such as alleviating pain, promoting tissue repair, and shortening disease duration. LIPUS can also mediate inflammation. This paper reviews the application of LIPUS in inflammation and discusses the underlying mechanism. In basic experiments, LIPUS can regulate inflammatory responses at the cellular level by affecting some signaling pathways. In a clinical trial, LIPUS has been shown to alleviate inflammatory responses efficiently. As a cheap, safe, and convenient physical method, LIPUS is promising as anti-inflammatory therapy.
\end{abstract}

Keywords: Low-intensity pulsed ultrasound (LIPUS); inflammation; signaling pathway; therapeutic ultrasound

Submitted May 22, 2020. Accepted for publication Sep 25, 2020.

doi: 10.21037/qims-20-680

View this article at: http://dx.doi.org/10.21037/qims-20-680

\section{Introduction}

Inflammation is characterized by redness, swelling, heat, and pain, and is a defensive response to stimuli such as toxins and pathogens (1). Inflammation has been shown to play an important role in many diseases, such as osteoarthritis (OA), neurodegenerative disorders, and trauma (2-4). Inflammatory disorders bring great pain and financial burden to those affected. However, there are currently few suitable anti-inflammatory drugs. Clinically, nonsteroidal anti-inflammatory drugs (NSAIDs) or corticosteroids are generally used to subdue inflammatory responses, both of which have clear side-effects, such as gastrointestinal reactions, renal dysfunction, increased risk of infection, and so on $(5,6)$.

Low-intensity pulsed ultrasound (LIPUS) is a form of ultrasound that delivers at a much lower intensity $\left(<3 \mathrm{~W} / \mathrm{cm}^{2}\right)$ than traditional ultrasound and outputs in the mode of pulse wave (7), which has therapeutic effects. However, until now, LIPUS has not been accurately defined. The following parameters are widely used: pulse frequency of $1.5 \mathrm{MHz}$, pulse repetition frequency of $1 \mathrm{kHz}$, and the spatial average temporal average intensity of $30 \mathrm{~mW} / \mathrm{cm}^{2}$ of the LIPUS transducer's surface area (8). As a physical therapy, LIPUS has been applied in many areas, including the musculoskeletal and nervous systems, dentofacial tissue, and others (8-10). In contrast with traditional drug therapy and invasive treatments, LIPUS works by emitting pulsed acoustic waves to specific regions, which is non-invasive and tolerable, with very minimal side effects. The therapeutic effects of LIPUS are mostly attributed to its non-thermal effects, predominantly cavitation, acoustic streaming, and acoustic radiation force. Cavitation, occurring in a liquid or liquid-like material, is considered to be associated with the changes of membrane permeability and activation of cells (11). Acoustic streaming, especially micro-streaming, is responsible for the diffusion rate and alteration of protein synthesis, cellular secretion, and sonoporation (12). Acoustic radiation force is capable of influencing the cardiovascular and nervous systems (13). Although the thermal effect of LIPUS is very limited because of its low intensity, it should still be considered when used in some temperature-sensitive situations, particularly when some enzymes, collagenase, 
and the nervous system are implicated. It is reported that thermal deactivation is one of the most important mechanisms in the denaturation of enzymes induced by LIPUS (14).

In recent years, physical therapy has been widely discussed, especially in terms of inflammation (15-17). In the past, physical therapy was mainly used in rehabilitation. But with the deepening of research, researchers have revealed the potential of physical therapy in mediating inflammation. For example, Chen et al. reported that extracorporeal shock wave therapy attenuated cyclophosphamide-induced acute interstitial cystitis in rats, which was initially a physical treatment for kidney stones (18). Gardner et al. reported that exercise therapy improved circulating markers of endothelium-derived inflammation in patients with peripheral artery disease (19). These findings suggest that physical therapy is a promising anti-inflammatory method (20). The physical therapy that is LIPUS has also attracted significant attention. Initially, LIPUS was used to promote tissue repair. It could accelerate wound healing, decrease edema, and soften scar tissue (21). These changes were partly ascribed to the effect of LIPUS on the inflammatory phase of the repair process (22). To date, LIPUS has been confirmed to regulate inflammatory responses in many fields. The underlying mechanism has been shown to be related to the alteration of cytokines and signaling pathways. Here, we review the application of LIPUS in inflammatory situations, including both experimental studies and clinical applications.

\section{Experimental study}

Many basic studies, both in vivo and in vitro, have accumulated regarding the role of LIPUS in inflammation. Multiple studies have also explored the underlying mechanisms of LIPUS. In this section, we review the application of LIPUS in inflammation at the cellular level (Table 1).

Table 1 The application of LIPUS in experimental study

\begin{tabular}{|c|c|c|c|}
\hline Targets cells & Sources & LIPUS parameters & Results \\
\hline \multirow[t]{5}{*}{ White cells } & $\begin{array}{l}\text { Nagata } \\
\text { et al. (4) }\end{array}$ & $\begin{array}{l}\text { A frequency of } 3 \mathrm{MHz} \text { with a spatially averaged intensity of } \\
30 \mathrm{~mW} / \mathrm{cm}^{2} \text { and pulsed 1:4 (2 ms on and } 8 \mathrm{~ms} \text { off) }\end{array}$ & $\begin{array}{l}\text { Decreasing the number of inflammatory } \\
\text { infiltrate cells (lymphocytes, plasma cells, } \\
\text { macrophages, and neutrophil leukocytes) }\end{array}$ \\
\hline & $\begin{array}{l}\text { Hsieh } \\
\text { et al. }(23)\end{array}$ & $\begin{array}{l}\text { A frequency of } 1.0 \mathrm{MHz} \text {, irradiation intensity of } 0.1 \mathrm{~W} / \mathrm{cm}^{2} \text { and } \\
20 \% \text { duty cycle for } 20 \text { min per treatment session }\end{array}$ & $\begin{array}{l}\text { Decreasing lymphocytic inflammatory } \\
\text { infiltration }\end{array}$ \\
\hline & $\begin{array}{l}\text { Signori } \\
\text { et al. (24) }\end{array}$ & $\begin{array}{l}\text { A frequency of } 1 \mathrm{MHz} \text {, an intensity of } 0.4 \mathrm{~W} / \mathrm{cm}^{2} \text { and } \mathrm{I}_{\text {SATA }} \\
0.08 \mathrm{~W} / \mathrm{cm}^{2}\end{array}$ & $\begin{array}{l}\text { Promoting neutrophils and monocytes } \\
\text { to surgical incision in the biceps femoris } \\
\text { muscle in rats at } 1 \text { hour post-surgery }\end{array}$ \\
\hline & $\begin{array}{l}\text { da Silva Junior } \\
\text { et al. (25) }\end{array}$ & $\begin{array}{l}\text { A frequency of } 1 \mathrm{MHz} \text { and medium intensity of } 0.4 \mathrm{~W} / \mathrm{cm}^{2} \text { in } \\
1: 5 \text { pulsed mode }\end{array}$ & $\begin{array}{l}\text { Reducing the number of neutrophils one } \\
\text { day after injury }\end{array}$ \\
\hline & $\begin{array}{l}\text { Montalti } \\
\text { et al. (26) }\end{array}$ & $\begin{array}{l}\text { A frequency of } 1.5 \mathrm{MHz}, 1: 4 \text { duty cycles and } \mathrm{I}_{\text {SATA }} \\
30 \mathrm{~mW} / \mathrm{cm}^{2}\end{array}$ & $\begin{array}{l}\text { Increasing inflammatory infiltration on TA } \\
\text { muscle repair after } 7 \text { days in cryoinjured rats }\end{array}$ \\
\hline \multirow{3}{*}{ Macrophages } & $\begin{array}{l}\text { Zhang } \\
\text { et al. }(27)\end{array}$ & A frequency of $1.5 \mathrm{MHz}, 20 \%$ duty cycle and $30 \mathrm{~mW} / \mathrm{cm}^{2}$ & $\begin{array}{l}\text { Suppressing the production of mature } 1 \mathrm{~L} 1 \beta \\
\text { in macrophages }\end{array}$ \\
\hline & $\begin{array}{l}\text { Ogata } \\
\text { et al. }(28)\end{array}$ & $\begin{array}{l}\text { A frequency of } 1.875 \mathrm{MHz} \text {, pulse repetition frequency } \\
4.90 \mathrm{kHz} \text {, number of cycles } 32 \text {, voltage applied to each } \\
\text { transducer element, } 17.67 \text { volts }(\mathrm{V}) \text {, and I I SPTA } 117-162 \mathrm{~mW} / \mathrm{cm}^{2}\end{array}$ & Attenuating macrophage infiltration \\
\hline & $\begin{array}{l}\text { Zheng } \\
\text { et al. (29) }\end{array}$ & $\begin{array}{l}\text { A frequency of } 1 \mathrm{MHz} \text {, duty cycle of } 20 \% \text {, pulse repetition } \\
\text { frequency of } 100 \mathrm{~Hz} \text {, output intensity of } 0.5 \mathrm{~W} / \mathrm{cm}^{2} \\
100 \mathrm{~mW} / \mathrm{cm}^{2} \mathrm{I}_{\text {SATA }}\end{array}$ & $\begin{array}{l}\text { Inhibiting the expression of pro-inflammatory } \\
\text { cytokines in macrophages. }\end{array}$ \\
\hline
\end{tabular}

Table 1 (continued) 
Table 1 (continued)

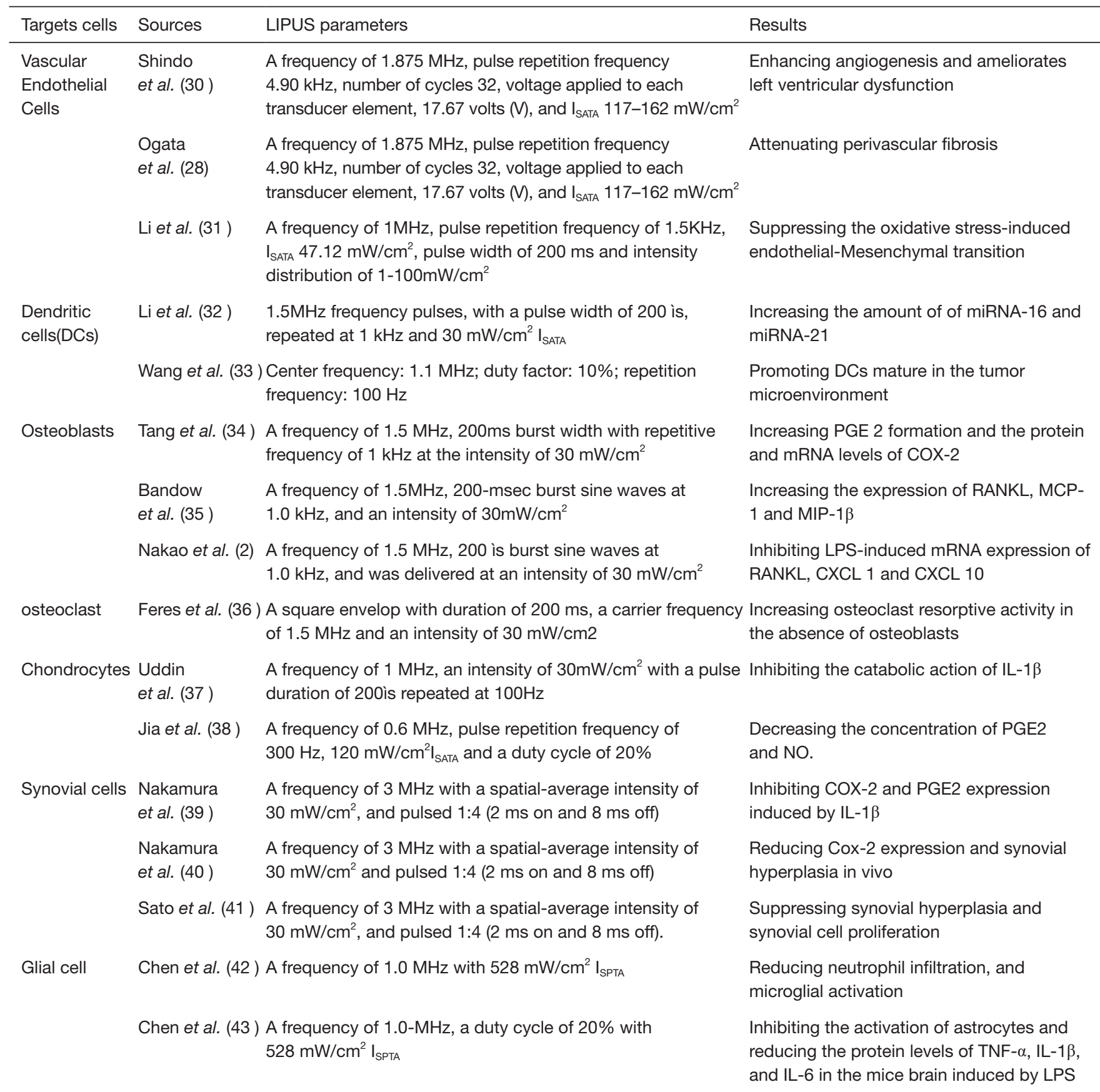

LIPUS, low intensity pulsed ultrasound; I IPTA spatial peak temporal average intensity; $I_{\text {SATA, }}$ spatial averaged-temporal intensity; LPS, Lipopolysaccharide; IL1 $\beta$, Interleukin 1 $\beta$; PGE 2, prostaglandin E2 ; COX-2, cyclooxygenase-2; RANKL, Receptor Activator for Nuclear Factor-кB Ligand; MCP-1, monocyte chemotactic protein 1; MIP, macrophage-inflammatory protein; CXCL, the C-X-C motif chemokine ligand; NO, Nitric Oxide; TNF- $\alpha$, Tumor Necrosis Factor $\alpha$. 
White blood cells

As we know, white blood cells play a key role in the repair process. After an injury, the inflammatory response is activated, and white blood cells are recruited to clean up foreign material, inhibit bacterial infection, and subsequently help orchestrate the tissue repair response (44). As time goes on, inflammation gradually subsides, and injured tissues begin to recover. If the infiltration of white blood cells is persistent, inflammation cannot subside, leading to tissue damage and fibrosis. It has been confirmed that LIPUS promotes the repair of injured tissues, and its effect is associated with the inflammatory infiltration stage of repair. On the one hand, LIPUS can accelerate tissue repair by increasing the infiltration of white blood cells. By increasing inflammatory infiltration, the inflammatory response is completed, and the injured tissue is advanced to the next phase more efficiently (22). For example, Signori el al. reported that LIPUS induced neutrophils and monocytes to the surgical incision in the biceps femoris muscle of rats at $1 \mathrm{~h}$ post-surgery (24), which was beneficial to form a barrier against the invasion of micro-organisms and clean necrotic parts. On the other hand, LIPUS can alleviate inflammatory infiltration, which is detrimental to repair in the late phase of inflammation. In a muscle injury model, caused by cryoinjury of the tibialis anterior (TA) muscle in rats, da Silva Junior et al. found LIPUS reduced the number of neutrophils 1 day after the injury, which minimized tissue damage caused by the release of reactive oxygen species, proteases, and other lysosomal constituents of these cells (25). Interestingly, Montalti et al. also reported that compared to untreated rats, the application of LIPUS $24 \mathrm{~h}$ after the surgical procedure increased inflammatory infiltration on TA muscle repair after 7 days in cryoinjured rats (26). However, granulation tissue and newly formed muscle fibers displayed better tissue structure organization in the LIPUS group after 13 days. Although the definite mechanism of LIPUS in repair is not clear, these differences possibly relate to inconsistencies in the degree of injury. In the study by Montalti et al., the injury was severe, which meant it required more inflammatory cells to infiltrate and more time to repair. The application of LIPUS accelerated this process. The improvement in tissue organization in the LIPUS group confirmed that LIPUS was beneficial for repair.

Moreover, inflammatory infiltration also plays a critical role in some inflammatory diseases. Inflammatory cells are recruited in the lesion and release proinflammatory cytokines, which lead to tissue damage. It has been reported that LIPUS also affects inflammatory infiltration in inflammatory diseases. Nagata et al. reported that the amount of infiltrating inflammatory cells (lymphocytes, plasma cells, macrophages, and neutrophil leukocytes) on the LIPUS-treated side was decreased significantly compared with that on the control side in the TA muscle in C57BL/6 mice injured by cardiotoxin (4). They also found that LIPUS decreased cyclooxygenase-2 (COX-2) gene and protein expression at the late stage in the injured TA muscle, which was typically considered proinflammatory. Consistently, Hsieh et al. reported that the infiltration of inflammatory cells was less apparent in the LIPUS-treated group in a post-traumatic knee OA model established by anterior cruciate ligament transection and meniscectomy in rats (23). There was a significant reduction in cellularity and lymphocytic inflammatory infiltration observed in the knee joint synovium of the LIPUS group as compared with the control group. Inflammatory infiltration in the lesion is often considered as a sign of early disease and results in pain, edema, and other symptoms. The early inflammatory reaction is a possible target for potential therapeutic intervention (45). These findings suggest that LIPUS has the potential to regulate inflammation in the lesion. Further clinical studies are required to investigate this mechanism.

Generally, LIPUS has a bi-directional effect on white blood cells. In the early stage of inflammation in repair, LIPUS promotes the infiltration of white blood cells, which accelerates wound cleaning and is beneficial to repair. And in the last stage of inflammation in repair and in some inflammatory diseases, LIPUS alleviates the infiltration, which prevents tissue damage. However, the underlying mechanism is still not clear.

\section{Macrophages}

Macrophages participate in immune and inflammatory responses. It has been reported that macrophages and monocytes are sensitive to biomechanical stimulation and distinct mechanical impacts are likely to induce different effects on macrophages (46-48). The ultrasound pressure wave has been proven to influence the behavior of macrophages (35).

In tissue repair, macrophages have been shown to exhibit critical regulatory activity at all stages of healing and fibrosis (49), and LIPUS can regulate the activity of macrophages in the repair process. For example, in a cryoinjury rat model, da Silva Junior et al. reported that LIPUS led to reductions in the number of M1 (inflammatory 


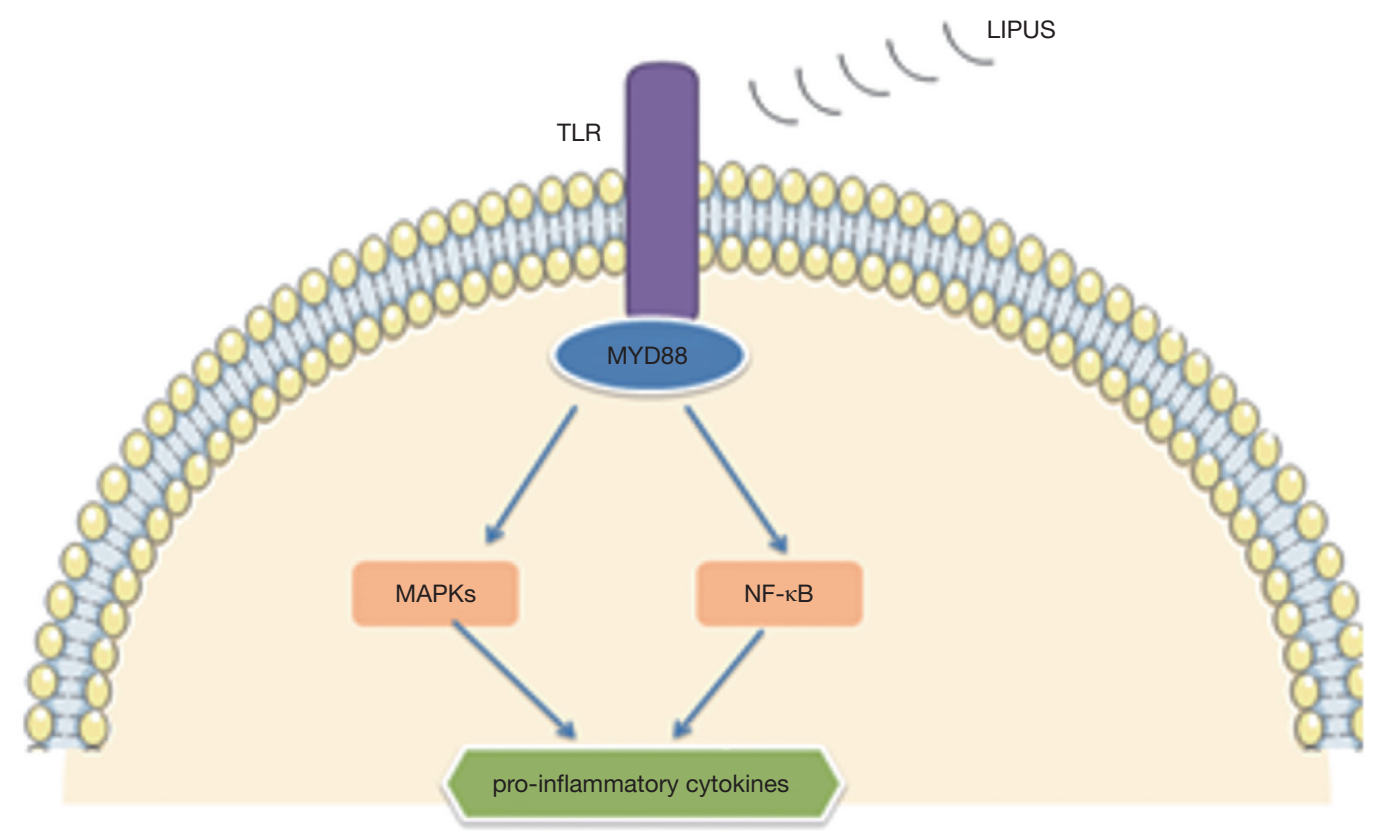

Figure 1 The MAPK signaling pathway and NF- $\kappa \mathrm{B}$ signaling pathway are mediated by LIPUS through TLR to regulate inflammatory responses. When exposed to LIPUS, the TLR/MyD88 complex is inhibited. The down-streaming signaling pathways (NF- $\mathrm{B}$ and MAPK signaling pathways) are also suppressed. These changes lead to the decrease of pro-inflammatory cytokines, such as TNF- $\alpha$, IL-1 $\beta$, IL-6, and so on. LIPUS, low intensity pulsed ultrasound; TLR, toll-like receptor; MYD88, myeloid differentiation factor 88; MAPKs, mitogenactivated protein kinases; NF- $\mathrm{B}$, nuclear factor $\kappa \mathrm{B}$; TNF- $\alpha$, tumor necrosis factor $\alpha$; IL-1 $\beta$, interleukin-1 $\beta$; IL-6, interleukin-6.

profile) macrophages after 1 day and increased the number of M2 macrophages (anti-inflammatory or reparative profile) after 2 days (25). The decrease of M1 macrophages suggested that LIPUS prevents persistent inflammatory responses in repair. The increase of M2 macrophages suggests that LIPUS is beneficial to the repair response. Generally, LIPUS can modulate the phenotype of macrophages in injured tissue to promote repair, but the specific mechanism remains unknown.

Lipopolysaccharide (LPS) is one of the primary pathogenic factors in many diseases, such as periodontitis, and macrophage cells are 1 of the target cells of LPS. Recently, in U937 macrophage cells, Zhang et al. reported that LIPUS alleviated the expression of inflammatory factors induced by LPS, such as tumor necrosis factor- $\alpha$ (TNF- $\alpha$ ), interleukin (IL)-1 $\beta$, IL-6, and IL-8 (1). Further, they revealed that this process was modulated by suppressing the toll-like receptor 4 (TLR 4)-nuclear factor $\mathrm{\kappa B}(\mathrm{NF}-\mathrm{\kappa B})$ signaling pathway (Figure 1). Zhang et al. also reported that LIPUS suppressed the production of mature $1 L 1 \beta$ in macrophages in a destabilization of the medial meniscus (DMM) mouse model made by surgery and air pouch model injected LPS (27). They found LIPUS inhibited the production of mature IL $1 \beta$ by enhancing autophagy flux, which was associated with the autophagymediated degradation of sequestosome-1 (SQSTM1), a receptor protein promoting ubiquitinated protein degradation, and the autophagic degradation of pyruvate kinase isoenzyme type M2 (PKM) in an SQSTM1dependent manner (Figure 2). Zheng et al. also reported that LIPUS treatment alleviated LPS-induced inflammatory response on RAW264.7 macrophage cells (29). In their experiment, LIPUS treatment decreased LPS-induced elevation of pro-inflammatory cytokines (TNF- $\alpha$ and IL-6) and activated caveolin-1. And the phosphorylation of $\mathrm{p} 38$ mitogen-activated protein kinase (MAPK) and extracellular signal-regulated kinase (ERK) was inhibited by LIPUS (Figure 3). Caveolin-1 is 1 of 3 structural proteins of caveolae, flask-shaped plasma membrane invaginations, and takes part in cell metabolism, proliferation, and inflammatory response (50-53). It is expressed ubiquitously in all cells and can be affected by many factors, such as shear stress alteration, some proinflammatory factors, and so on. Besides, Ogata et al. reported that the macrophage 


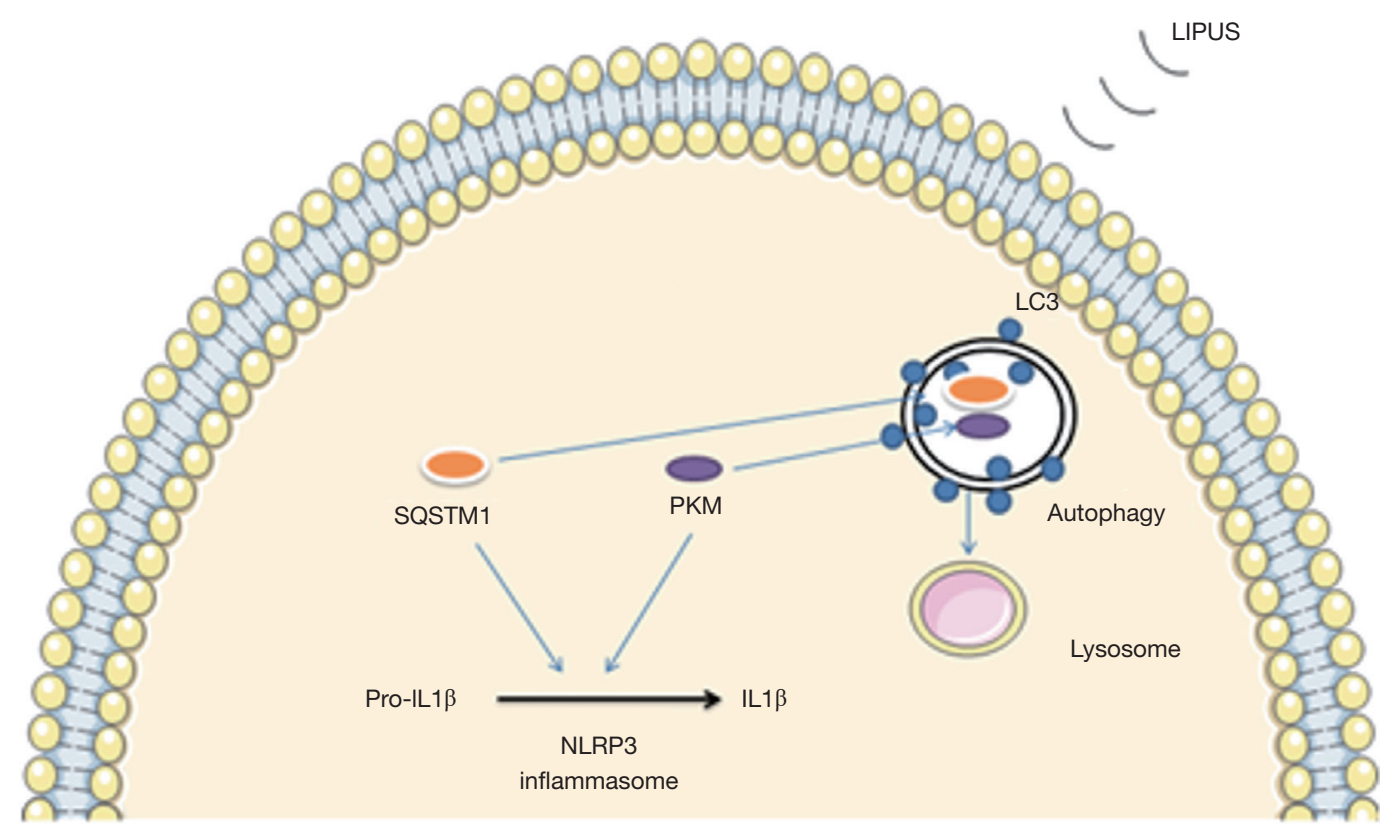

Figure 2 The production of mature IL-1 $\beta$ in macrophages is suppressed by LIPUS. LIPUS enhances the autophagy flux in macrophages, which promotes the degradation of SQSTM 1 and PKM in autophagy-dependent way. The decrease of SQSTM 1 and PKM inhibits the production of mature IL-1 $\beta$. SQSTM 1-dependent autophagic degradation of PKM 2 in macrophages. LIPUS, low intensity pulsed ultrasound; SQSTM 1, sequestosome 1; PKM 2, pyruvate kinase M2; NLRP3, NLR family, pyrin domain containing 3; IL1 $\beta$, interleukin 1 $\beta$.

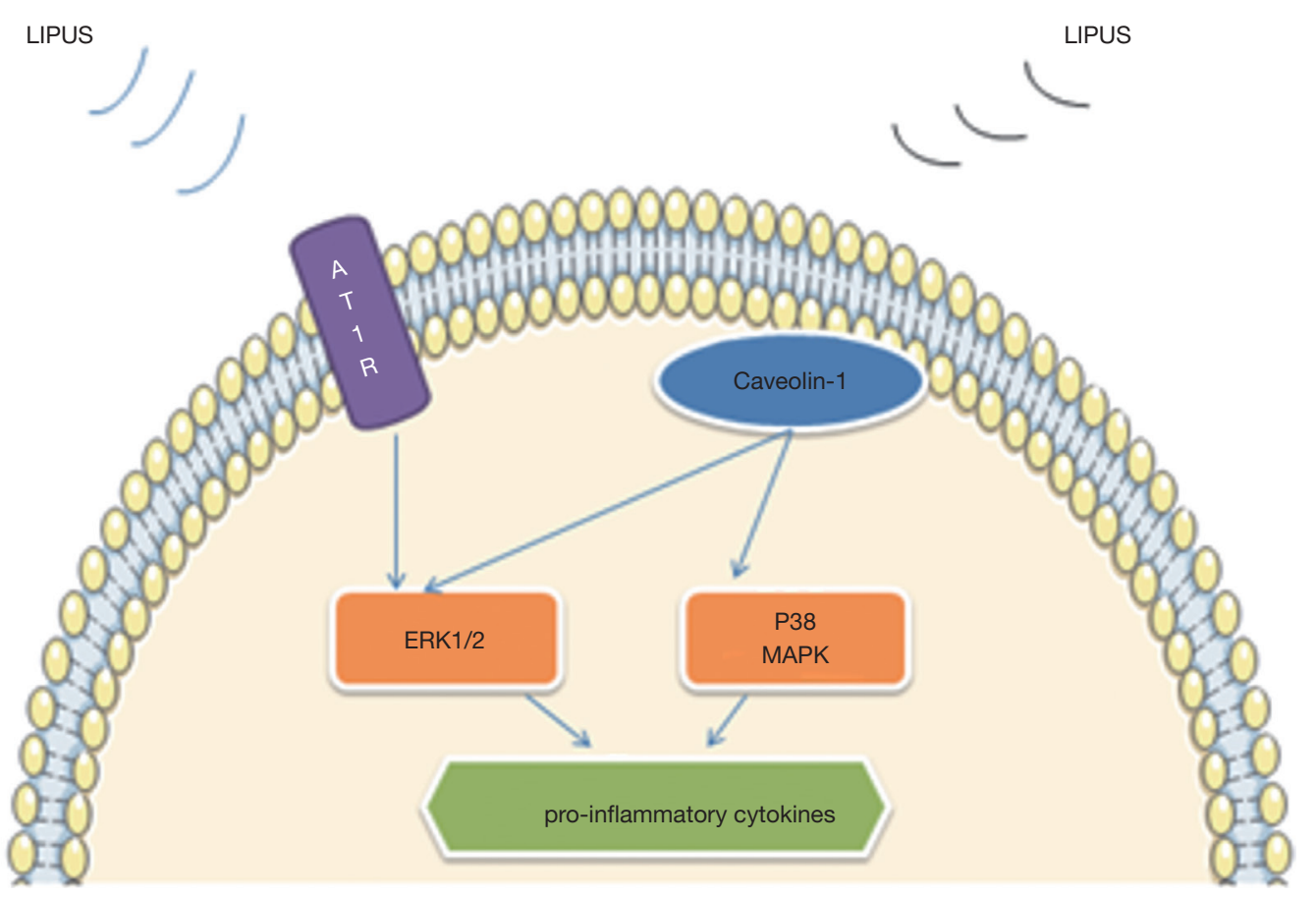

Figure 3 The MAPKs signaling pathway is affected by LIPUS through AT1 and caveolin-1 to mediate inflammation. The phosphorylation of ERK is induced by LIUPS through AT 1, and this increases the expression of inflammatory cytokines. However, the activation of caveolin-1 induced by LIPUS can suppress the expression of inflammatory kinases through MAPKs. LIPUS, low intensity pulsed ultrasound; AT 1, angiotensin type 1; MAPKs, mitogen-activated protein kinases; ERK 1/2, extracellular signal-regulated kinase. 
infiltration was significantly attenuated after irradiation with LIPUS in left ventricle pressure-overloaded hearts in mice induced with transverse aortic constriction (28).

Overall, LIPUS can regulate the phenotype of macrophages (decrease M1 macrophages and increase M2 macrophages) in repair and prevent macrophage infiltration in inflammatory diseases. These effects are associated with signaling pathways, such as the MAPK and NF- $\mathrm{BB}$ signaling pathways.

\section{Vascular endothelial cells (VECs)}

VECs can sense blood flow-induced mechanical stimuli and convert these stimuli into a sequence of biological responses (54). This suggests VECs may sense other mechanism stimuli, such as LIPUS. Recently, Shindo et al. stated that LIPUS enhanced angiogenesis and ameliorated left ventricular dysfunction in a mouse model of acute myocardial infarction (ligation of the proximal left anterior descending coronary artery) (30). They suggested that caveolin-1 played a critical role by transmitting the mechanical stimuli to intracellular signaling pathways with subsequent phosphorylation of Fyn, focal adhesion kinase (FAK), ERK1/2, and protein kinase B (Akt), and resultantly enhanced the expression of vascular endothelial growth factor (VEGF) and angiogenesis. These findings suggest that LIPUS can possibly regulate anti-inflammatory responses in VECs. Previous studies demonstrated that shock wave therapy could improve heart function through its anti-inflammatory effects (55). The therapeutic effects of shock wave therapy and LIPUS are both caused by the mechanical energy from acoustic waves. For some diseases, shock wave therapy and LIPUS have similar therapeutic effects, such as promoting fracture repair, improving erectile function, and protecting cartilage tissue (56-58). Therefore, LIPUS seems to also exert anti-inflammatory effects in VECs. Recently, Ogata $e t$ al. reported myocardial perivascular fibrosis was significantly attenuated after irradiating with LIPUS in chronic left ventricular pressure overload mice (28). They indicated that LIPUS therapy attenuated perivascular fibrosis by suppressing anti-inflammatory responses; however, the mechanism is unknown. In human aortic endothelial cells, Li et al. reported that LIPUS produced cytoprotective effects against oxidative injuries to endothelial cells through suppressing the oxidative stress-induced endothelialmesenchymal transition and limiting cell migration and excessive extracellular matrix deposition (31). In addition, they found the phosphatidylinositol 3-kinase (PI3K)/Akt pathway was activated by LIPUS under oxidative stress. Activation of PI3K increased the expression of endothelial markers (CD31 and VE-cadherin) and decreased the expression of mesenchymal markers (FSP-1 and $\alpha$-SMA) (Figure 4). Oxidative stress also exists in inflammation. It has been confirmed that the PI3K/Akt pathway plays a critical role in inflammation in vascular endothelial cells. Thus, LIPUS may exert its anti-inflammatory effects through suppressing oxidative stress and activating the PI3K/Akt pathway in VECs.

Generally, LIPUS has protective effects on vascular endothelial cells. The protective effects can partly ascribe to the anti-inflammatory effects of LIPUS. The Caveolin-1 and PI3K/Akt signaling pathways may be one of the underlying mechanisms.

\section{Dendritic cells (DCs)}

DCs are specialized antigen-presenting cells, which have an important involvement in the induction and amplification of immune responses during inflammatory reactions $(59,60)$. DCs produce proinflammatory cytokines and exosomes, which can release some anti-inflammatory compounds, such as microRNAs (miRNAs) (61). The miRNAs regulate gene expression post-transcriptionally, function within the cells in which they are transcribed, and several specific miRNAs (miRNA-145 and miRNA-146a) have recently demonstrated an ability to suppress inflammatory immune responses (62). For example, Hui et al. reported that miRNA-145 attenuated high glucose-induced oxidative stress and inflammation in retinal endothelial cells (63). Exosomes have been reported as potentially promising novel therapeutics for inflammation $(64,65)$. Previous studies have indicated that DCs can sense the stimulation of ultrasound waves (66). Recently, Yang et al. also reported that LIPUS enhanced DC-derived exosome biogenesis and docking (67). In an in vitro experiment, Li et al. explored the effects of LIPUS for bone marrow dendritic cells (BMDCs) in atherosclerosis (AS). They found that the exosomes derived from LIPUS-treated BMDCs contained higher amounts of miRNA-16 and miRNA-21, which possessed anti-inflammatory functions (32). Human umbilical vein endothelial cells injected with these exosomes expressed less intercellular cell adhesion molecule-1 (ICAM-1) and vascular cell adhesion molecule-1 (VCAM-1) and had lower 


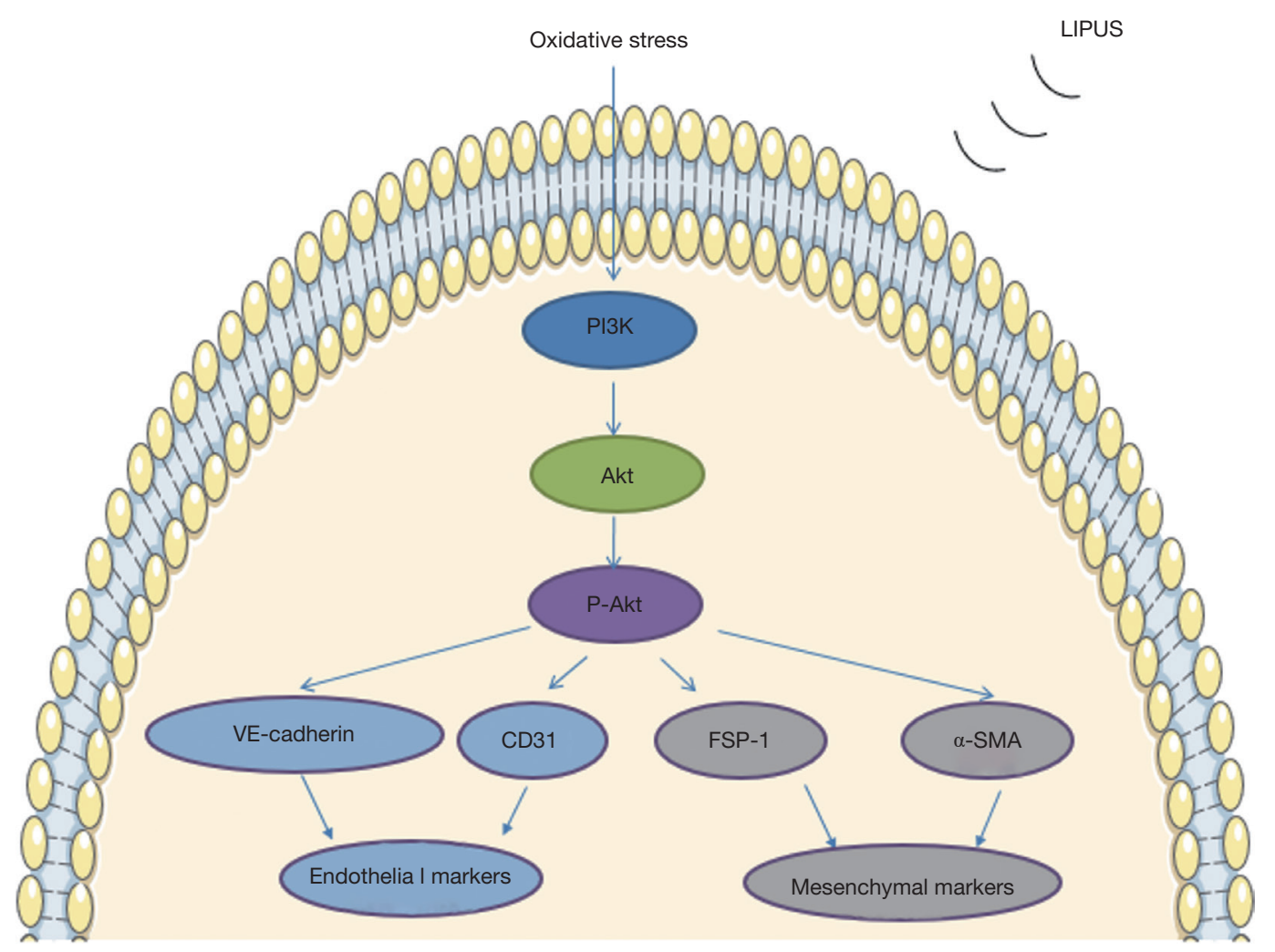

Figure 4 Oxidative injuries are alleviated by LIPUS through the activation of the PI3K-Akt signaling pathways. LIPUS can protect vascular endothelial cells from oxidative injuries. Under oxidative stress, LIPUS activates PI3K-Akt signaling pathways. Activation of PI3K increases the expression of endothelial markers (CD31 and VE-cadherin) and decreases the expression of mesenchymal markers (FSP-1 and $\alpha$-SMA). LIPUS, low intensity pulsed ultrasound; PI3K, phosphatidylinositol 3-kinase; Akt, protein kinase B; FPS-1, fibroblast specific protein; $\alpha$-SMA, $\alpha$-smooth muscle actin.

activity of NF-kB signaling in response to TNF- $\alpha$ (Figure 5). Previous studies revealed that miRNA-16 inhibited the activity of the NF- $\mathrm{KB}$ signaling pathway through suppressing the expression of IкB kinase, and miRNA-21 limited the activation of the NF- $\mathrm{KB}$ signaling pathway through inhibiting the expression of proinflammatory factors $(68,69)$. Consistently, Li et al. also found that exosomes dose-dependently attenuated TNF- $\alpha$-induced p65 phosphorylation and stimulated inhibitory-kB kinase $\alpha$ (IKK $\alpha)$ degradation. These findings suggest that LIPUS can alleviate inflammations through mediating the exosome of DCs.

However, in a tumor microenvironment, DCs become immature and deprived of their abilities of antigenpresenting cells, which contributes to the state of immune equilibrium and immune escape (70). It has been reported that LIPUS can promote immature DCs to develop into mature DCs, which would enhance the inflammatory immune response in tumor tissue. The mature DCs enriched microenvironment is not favorable for the survival of tumors. Wang et al. reported that LIPUS facilitated DCs maturation and increased the expression of IL-10, interferon (IFN) $-\gamma$, and TNF- $\alpha$, which was not conducive to the survival of tumor tissue (33). It suggests that LIPUS is harmful to the survival of tumors by enhancing the inflammatory response.

In conclusion, DCs can sense the stimuli of LIPUS and translate this stimulus into bioeffects to regulate inflammation. The DC-derived exosome and NF- $\kappa \mathrm{B}$ signaling pathways may be involved in this process. In special tumor microenvironments, LIPUS promotes mature DCs to active the inflammatory immune response within tumors.

\section{Osteoblasts}

Osteoblasts, differentiated from mesenchymal stem cells 


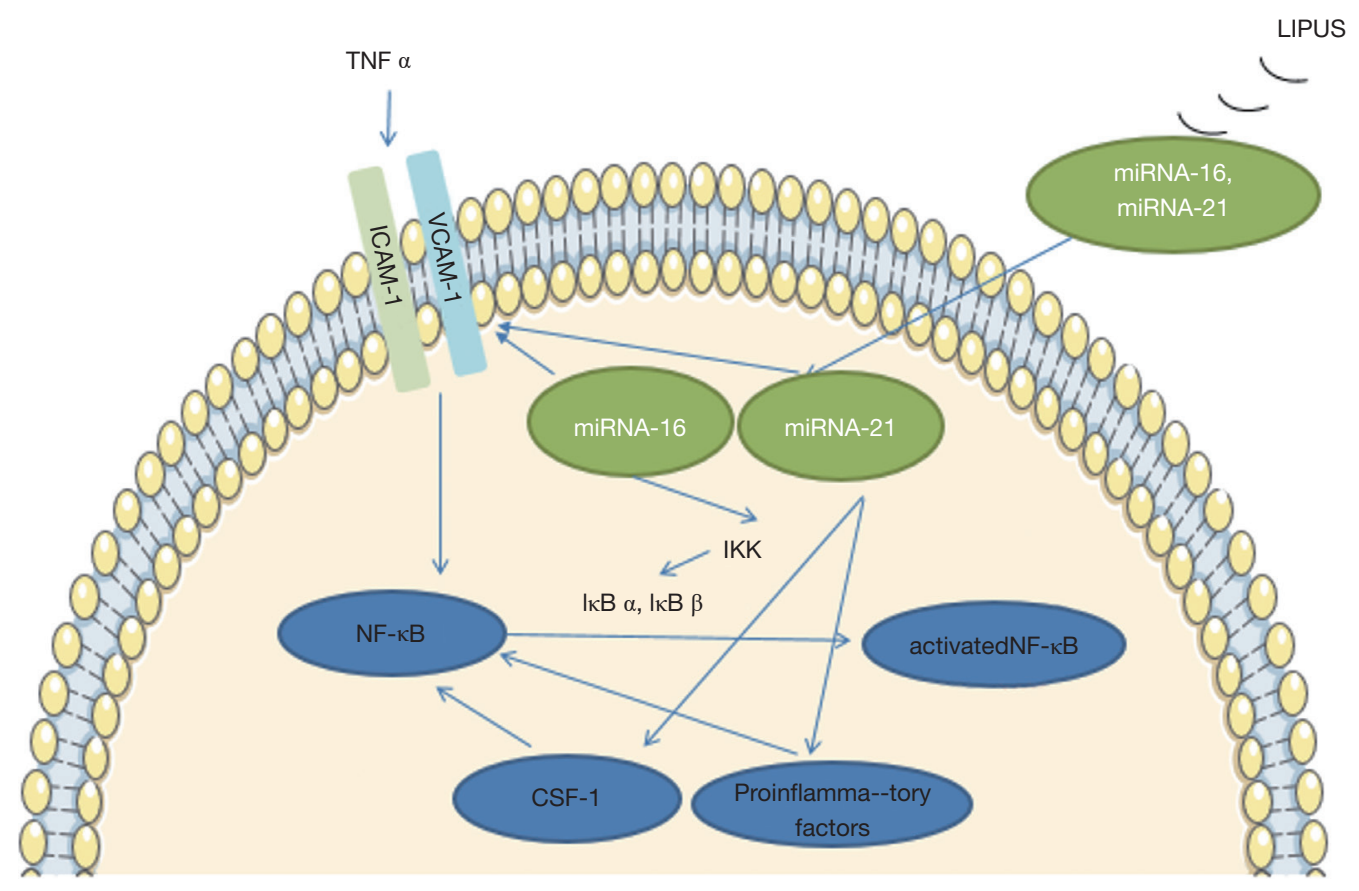

Figure 5 An anti-inflammatory effect is exerted by LIPUS by increasing miR-16 and miR-21 in exosomes. LIPUS increases miRNA-16 and miRNA-21 in exosomes derived from BMDCs. Human umbilical vein cultured endothelial cells preincubated with exosomes from LIPUS-treated BMDCs express less ICAM- 1 and VCAM- 1 and have lower activity of NF- $\kappa$ B signaling in response to TNF- $\alpha$. miRNA-16

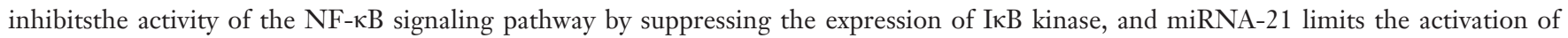
the NF- $\mathrm{kB}$ signaling pathway by inhibiting the expression of proinflammatory factor. BMDCs, bone marrow dendritic cells; LIPUS, low intensity pulsed ultrasound; $\mathrm{NF}-\kappa \mathrm{B}$, nuclear factor $\kappa \mathrm{B}$; IKK, inhibitor of nuclear factor $\kappa \mathrm{B}$ kinase; I $\mathrm{B} \alpha$, inhibitor of nuclear factor $\kappa \mathrm{B} \alpha$; VCAM-1, vascular cell adhesion molecule-1; ICAM-1, intercellular adhesion molecule-1.

(MSCs), are one of the main cells in bone. Osteoblasts have been confirmed to express some inflammatory chemokines, such as monocyte chemotactic protein 1 (MCP-1), macrophage-inflammatory protein (MIP)-1, regulated upon activation normal $\mathrm{T}$ cell expressed and secreted factor (RANTES), and Interleukin-8 (IL-8) $(35,71)$. Osteoblasts are also able to sense the stimuli of LIPUS.

It is recognized that inflammatory cytokines are critical for fracture healing $(72,73)$; they promote the proliferation and differentiation of MSCs and osteoprogenitor cells, which are important to bone remodeling $(74,75)$. As mentioned above, osteoblasts can release inflammatory cytokines after a fracture. Findings have indicated LIPUS could enhance cyclooxygenase-2 (COX-2) gene expression and subsequently enhance endogenous prostaglandin E2 (PGE2) synthesis in various osteoblastic cell lineages $(76,77)$. Consistently, Tang et al. reported that LIPUS promoted the production of COX-2 and PGE2 (34). The role of PGE 2 is essential in fracture healing and stimulates bone formation and resorption. Bandow et al. also reported that the expression of MIP- 1 and MIP-1 $\beta$ mRNA was increased by LIPUS more efficiently in differentiated osteoblasts, which was caused by LIPUS-induced ERK phosphorylation through angiotensin type 1 (AT1) receptor (Figure 3) (35). These findings suggest that LIPUS promotes the release of inflammatory cytokines in osteoblasts and facilitates bone remodeling. It has also been confirmed that LIPUS has an impact on osteoclasts. As regulators of mineral metabolism in the case of fracture, osteoclasts resorb necrotic bone fragments and the necrotic ends of the fractured bone and initiate the process of remodeling (73). Feres et al. reported that LIPUS increased osteoclast resorptive activity in the absence of osteoblasts in RAW 264.7 cells (36). This result suggests that LIPUS can also promote the repair of fracture by promoting bone absorption.

Interestingly, osteoblasts also play an important role in some inflammatory bone diseases. Under the stimuli of pathogen-associated molecular patterns, osteoblasts 
express inflammatory cytokines, which can aggravate inflammation in lesions. It has been reported that LIPUS has a therapeutic effect on these diseases by regulating the activity of osteoblasts. For example, Nakao et al. recently reported that LIPUS effectively inhibited LPS-induced mRNA expression of receptor activator for NF- $\mathrm{KB}$ ligand (RANKL), the C-X-C motif chemokine ligand (CXCL), 1, and CXCL 10 in mouse osteoblast cell line and calvariaderived osteoblasts, which suggested LIPUS alleviated inflammatory responses (2). Further, they found that LIPUS inhibited the formation of toll-like receptor (TLR4)/ myeloid differentiation factor 88 (MyD88) complex, which suggested that LIPUS exerted anti-inflammatory effects on LPS stimulated osteoblasts by inhibiting TLR4 signal transduction (Figure 1). However, it is unknown how the TLR4/MyD88 complex formation is inhibited by LIPUS. As a pathogenic factor, LPS plays an important role in some bone inflammatory diseases, such as arthritis and periodontitis. These findings suggest that LIPUS is a potential therapy for inflammatory bone diseases.

In conclusion, osteoblasts, as inflammatory regulators in bone tissue, can be regulated by LIPUS promotion through mediating the inflammatory cytokines released by osteoblasts are mediated by LIPUS to promote fracture healing and suppress inflammation in inflammatory bone diseases. The underlying mechanism is related to some signaling pathways such as the MAPK, NF- $\mathrm{BB}$, and TLR signaling pathways.

\section{Chondrocytes}

Chondrocytes, the cartilage cells, can express proinflammatory cytokines under the stimulation of inflammation $(78,79)$. These inflammatory cytokines are implicated in the damage of chondrocytes; for example, IL-1 can induce chondrocyte apoptosis (80). It has been reported that chondrocytes are highly mechanosensitive $(81,82)$, which suggests they can sense the stimuli of LIPUS. In human cartilage explants, Uddin et al. found that LIPUS inhibited the expression of IL-1 receptor type 1 (IL-1R1) in the presence of IL-1 $\beta$, making chondrocytes less susceptible to the catabolic and inflammatory effects of IL-1 $\beta$ (37). Consistently, in an OA model, excising the complete medial meniscus and both cruciate ligaments of rabbits, Jia et al. reported that LIPUS down-regulated apoptosis and reduced inflammatory mediators (PGE2 and nitric oxide $[\mathrm{NO}]$ ) in chondrocytes (38). These findings suggest that LIPUS can attenuate inflammation in chondrocytes, which protects articular cartilage. Recently, Sahu et al. also reported that continuous low-intensity ultrasound could repair cartilage in a pro-inflammatory environment by inhibiting the activation of NF- $\kappa \mathrm{B}$ induced by TNF- $\alpha$ and IL-1 $\beta$ in bovine osteochondral explant (83). Continuous ultrasound and pulsed ultrasound have been confirmed to have similar bioeffects. For example, they can both be used to improve endothelial function, alleviate pain, and improve physical disability (84-86). Continuous ultrasound produces more significant thermal effects than pulsed ultrasound when the parameters are the same $(87,88)$. As far as we know, the therapeutic effect of low-intensity ultrasound is mainly caused by mechanical effects. But the thermal effect of ultrasound is inevitable, which increases the temperature of and may impair tissue. Therefore, LIPUS seems to be a better candidate than continuous ultrasound.

In clinical practice, there is a lack of methods to protect cartilage tissue. It has been revealed that LIPUS can prevent chondrocytes from inflammatory damage, which presents LIPUS as a promising method to ease this situation; however, the underlying mechanism is still unknown.

\section{Synovial cells}

The synovial membrane is a metabolically active tissue, which is susceptible to inflammation $(89,90)$. Under the stimuli of inflammation, the metabolism of the synovial membrane becomes imbalanced, giving rise to the early pathogenesis of some diseases, such as rheumatoid arthritis (RA) and OA (91). It has been reported that LIPUS is able to regulate synovial cells. For example, exposing rabbit knee synovial membrane cell line (HIG-82) to LIPUS, Nakamura $e t$ al. found LIPUS exposure down-regulated COX-2 and PGE2 expression, and up-regulated hyaluronan synthase (HAS) 2 and HAS 3 expression in IL-1 $\beta$ stimulated synovial membrane cells, leading to the promotion of the anti-inflammatory system (39). Interestingly, in another study, they found LIPUS suppressed the proliferation and growth of synovial cells stimulated with IL- $1 \beta$ or TNF- $\alpha$ in HIG-82 and reduced COX-2 expression and synovial hyperplasia in MRL/lpr mice, a model of RA (40). Similarly, Sato et al. reported that LIPUS could mediate synovial cell proliferation and apoptosis to inhibit the synovial hyperplasia via the integrin/FAK/MAPK pathway in HIG82 (Figure 6) (41). We understand that abnormalities of hyaluronan metabolism and synovial hyperplasia are characteristics of synovial inflammation. These findings show that LIPUS can improve hyaluronan metabolism 


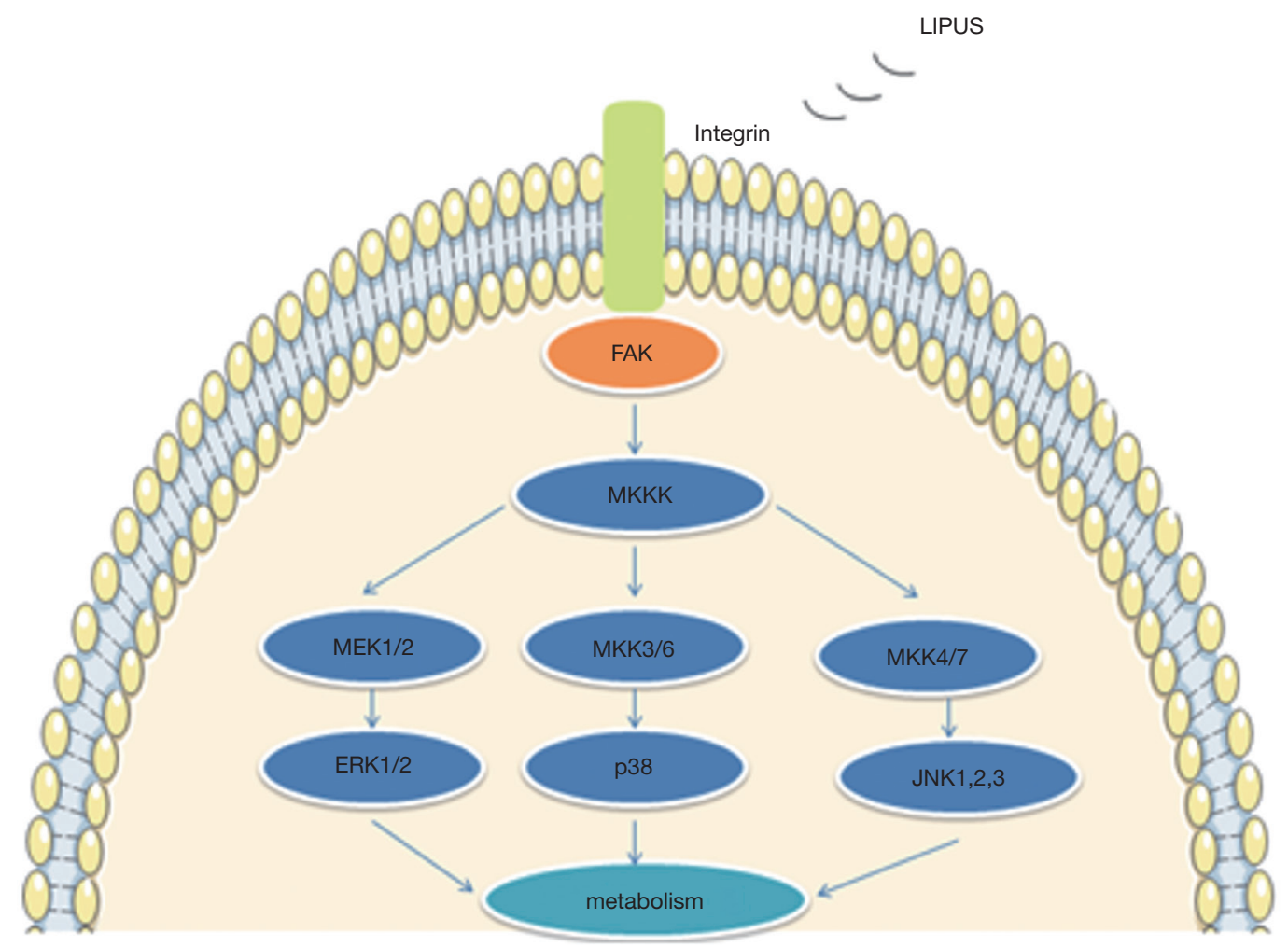

Figure 6 The influence of LIPUS on the integrin/FAK/MAPK signaling pathway to mediate inflammation. LIPUS induces the phosphorylation of integrin and FAK. The down-streaming MAPKs signaling pathways are also activated by LIPUS. These changes may result in the inhibition of synovial hyperplasia. LIPUS, low intensity pulsed ultrasound; FAK, focal adhesion kinase; MKKK, mitogenactivated protein kinase kinase kinase; MKK, mitogen-activated protein kinase kinase; JNK, c-Jun N-terminal kinase; ERK, extracellular signal-regulated kinase.

and inhibit synovial hyperplasia; thus, LIPUS appears to be a suitable therapeutic candidate for treating synovial inflammation.

\section{Glial cells}

Glial cells, an important part of the nervous system, are essential in neuroinflammatory reactions (92-94). The activation of glial cells is a characteristic of neuroinflammation, and inflammatory cytokines released by glial cells are associated with nerve injury. As a physical stimulation, LIPUS has been widely used in nervous system pathologies to modulate ion channels, promote nerve regeneration, and regulate neuronal function (9598). It was recently discovered that LIPUS plays a role in neuroinflammation. In cortical impact injury mice, Chen et al. reported that LIPUS reduced neutrophil infiltration and microglial activation in the injured brain (42). They also reported LIPUS inhibited the activation of astrocytes and significantly reduced the protein levels of TNF- $\alpha$, IL- $1 \beta$, and IL- 6 in the mice brain induced by LPS. Chen et al. also indicated that the anti-inflammatory effects of LIPUS might be due to the attenuation of TLR4/NF$\kappa \mathrm{B}$-induced inflammation signaling (43). In their studies, LIPUS suppressed the expression of TLR4/NF- $\kappa B$ pathway-related mediators, including upstream factors (TLR4/NF- $\kappa B$ ) and downstream factors (TNF- $\alpha$, IL-1 $\beta$, and IL-6) expression. Glial cells have also been shown to play a critical role in Alzheimer's disease, Parkinson's disease, and epilepsy (99-101). These findings suggest LIPUS can inhibit the activation of glial cells, so LIPUS may possibly be an effective treatment for those diseases.

Interestingly, it has also been reported that LIPUS promotes peripheral nerve regeneration and mediates the activity of Schwann cells (102). As we understand, the presence of inflammation can prevent nerve repair. It has 
Table 2 The application of LIPUS in clinic

\begin{tabular}{|c|c|c|c|}
\hline Sources & Samples & The parameters of LIPUS & Results \\
\hline Cui et al. (108) & 120 patients & $\begin{array}{l}\text { A pulse duration time-to-pulse rest time ratio of } 1: 4 \text { (200 is:800 is) at } \\
1,000 \mathrm{~Hz} \text {, a frequency of } 1.7 \mathrm{MHz} \text { and } 300 \mathrm{~mW} / \mathrm{cm}^{2} \text { I }_{\text {SATA }}\end{array}$ & $\begin{array}{l}\text { Safely and effectively improving } \\
\text { erectile dysfunction }\end{array}$ \\
\hline $\begin{array}{l}\text { Cruz } \\
\text { et al. (84) }\end{array}$ & $\begin{array}{l}42 \text { health } \\
\text { volunteers }\end{array}$ & $1 \mathrm{MHz}, 20 \%$ duty cycle ( $2 \mathrm{~ms}$ on, $8 \mathrm{~ms}$ off), and $0.08 \mathrm{~W} / \mathrm{cm}^{2} \mathrm{I}_{\text {SATA }}$ & Improving endothelial function \\
\hline $\begin{array}{l}\text { Hauck } \\
\text { et al. (109) }\end{array}$ & $\begin{array}{l}30 \text { health } \\
\text { volunteers }\end{array}$ & $\begin{array}{l}1 \mathrm{MHz} \text { and } 3 \mathrm{Mhz} \text {, a } 20 \% \text { duty cycle ( } 2 \text { milliseconds on, } 8 \\
\text { milliseconds off) and an intensity of } 0.08 \mathrm{~W} / \mathrm{cm}^{2} \mathrm{I}_{\text {SATA }}\end{array}$ & Improving endothelial function \\
\hline $\begin{array}{l}\text { Feizabadi } \\
\text { et al. (110) }\end{array}$ & 14 patients & $1 \mathrm{MHz}$, an intensity of $1 \mathrm{~W} / \mathrm{cm}^{2}$ and $0.5 \mathrm{~W} / \mathrm{cm}^{2}$ and $10 \%$ duty cycle & $\begin{array}{l}\text { Decreasing the } \mathrm{S} \text {. aureus population } \\
\text { in chronic rhinosinusitis patients }\end{array}$ \\
\hline
\end{tabular}

$\mathrm{I}_{\text {SPTP, }}$ spatial peak temoral peak intensity; $\mathrm{I}_{\text {SATA, }}$ spatial averaged-temporal intensity.

been found that shock wave therapy promotes peripheral nerve regeneration through its anti-inflammatory effects (103). As mentioned above, LIPUS is similar to shock wave therapy. So, it seems that the effects of LIPUS in nerve regeneration are partly achieved through an antiinflammatory mechanism.

Generally, LIPUS prevents the activation of glial cells in the central nervous system and possibly plays an antiinflammatory role in peripheral nerve repair. The TLR and $\mathrm{NF}-\kappa \mathrm{B}$ signaling pathways seem to be involved.

\section{Clinical application}

The Food and Drug Administration (FDA) has approved LIPUS as a physical therapy to use in accelerating the repair of fresh fractures and treating fractures at risk of non-union $(7,104)$. Although LIPUS has been widely used in clinical research, there are few studies regarding its use in inflammation $(17,105)$ (Table 2). In a pilot study, Samuels et al. recruited 20 patients suffering from venous ulcers, and LIPUS was used as the therapeutic tool (106). They tracked a reduction in wound size on a weekly basis. Their results showed that LIPUS wasbeneficial for treating venous ulcers. Similarly, in an 8 patient pilot study, Bajpai et al. reported that diabetic ulcers treated with ultrasound showed a significantly faster closure rate than sham-treated ulcers (107). Moreover, they confirmed that ultrasound-induced healing was associated with a reduction in the M1/M2 score, which indicated a reduction of inflammation in the treated wounds. In their study, all healing ulcers showed a decrease in the M1/M2 score over time, while all non-healing ulcers showed an increase in the score over time. Recently, Cui et al. conducted a multicenter, randomized, double-blind, sham-controlled clinical study including 120 patients (108), and reported that LIPUS could safely and effectively treat patients with mild to moderate erectile dysfunction (ED) without significant adverse events. This effect was related to the mechanical force of LIPUS being able to restore the pathological changes of the corpus cavernosum. However, they did not explore the underlying mechanism of LIPUS; they simply speculated the anti-inflammatory effects of LIPUS might be involved, which required further investigation to confirm. The anti-inflammatory effect of LIPUS is also thought to be one of the mechanisms for alleviating pain, inducing dental root resorption, and promoting lumbar spondylolysis repair in patients (111-113). Interestingly, in a randomized, clinical trial, Cruz et al. reported that LIPUS could improve endothelial function in humans by increasing NO production, which suggested that LIPUS had anti-inflammatory vascular effects (84). Consistently, Hauck et al. reported both continuous or pulsed ultrasound could improve endothelial function in a randomized clinical trial of 30 patients (109).

It appears that LIPUS is also efficient at treating bacterial infection. For example, Feizabadi et al. reported that LIPUS decreased the population of Staphylococcus aureus in chronic rhinosinusitis patients (110). Karosi et al. exposed nasal polyps removed from a patient with chronic rhinosinusitis to low-intensity continuous ultrasound (114) and found 
the inflammatory cell count was significantly decreased in the sub-epithelial layer of nasal polyps after irritation. This antibiotic effects of low-intensity ultrasound may be attributed to the destruction of the biofilm structure of bacterium caused by cavitation (115). In general, LIPUS, as a non-invasive, cheap, and convenient method, is promising in clinical settings.

\section{Prospect and limitation}

Inflammation, a defensive bodily response, aggravates damage, hinders repair, and delays recovery. As a physical tool, LIPUS continues to attract the attention of many researchers. It has been confirmed that LIPUS can regulate multiple cells to mediate inflammatory responses through the activation or inhibition of signal pathways. Some clinical studies have also confirmed that LIPUS is effective at alleviating inflammatory responses. These findings indicate that LIPUS is a promising anti-inflammatory therapy. Although the effect of LIPUS has been explored across many diseases, there are limited papers regarding metabolic diseases, such as diabetes and hyperlipidemia. It has been confirmed that inflammation plays a critical role in these diseases. For example, chronic inflammation has been demonstrated to be a key player in the development of diabetes and its complications (116-118). The cells involved in these diseases, including adipocytes, have been shown to respond under the stimuli of LIPUS $(119,120)$. It is possible that the anti-inflammatory effects of LIPUS could play an important role in the treatment of diabetes, and future research should be conducted.

Another use of LIPUS is in tissue engineering; for example, LIPUS has been used to promote the proliferation and differentiation of MSCs (121-123). Inflammation can inhibit the ability of self-renewal and tissue reconstitution of stem cells. Basic experiments have reported no obvious inflammatory reaction when used stem cells were combined with LIPUS, but a slight inflammatory response in the absence of LIPUS (124,125). Yang et al. reported that LIPUS could mediate exosomes produced by MSCs by increasing exosome biogenesis, docking mediators, and enhancing extracellular vesicles and exosomes to deliver their anti-inflammatory molecules to target cells (67). These findings suggest that LIPUS can alleviate inflammation in stem cells, which can influence their proliferation and differentiation.

There are also some limitations to the use of LIPUS. First, the specific LIPUS device and parameters are different among individual experiments. Different parameters can lead to different results, as it has been confirmed in previous studies (126,127). Moreover, LIPUS does not yet have a precise definition. Generally, parameters of LIPUS include the frequency of $1-3 \mathrm{MHz}$, intensity ranging from $0.02-1 \mathrm{~W} /$ $\mathrm{cm}^{2}$, pulse repetition rates of $0.1-1 \mathrm{KHZ}$, and duty cycles of 20-50\% (122). The following parameters are widely used: pulse frequency of $1.5 \mathrm{MHz}$, pulse repetition frequency of $1 \mathrm{kHz}$, spatial average temporal average intensity of $30 \mathrm{~mW} / \mathrm{cm}^{2}$ of the LIPUS transducer's surface area (8). Second, clinical data is lacking; although there are some clinical studies, the sample sizes have been small. Recently, the therapeutic value of LIPUS has been questioned. In 2 clinical trials, respectively, including 501 and 62 patients, it was indicated that LIPUS had no effect in bone healing $(128,129)$. Tarride et al. also reported that LIPUS is not cost-effective for fresh tibial fractures (130). Further studies are required to confirm the effectiveness of LIPUS. Third, the definite mechanism of LIPUS is unknown. It has been demonstrated that LIPUS can regulate a broad range of inflammatory cytokines to mediate inflammation, irrespective of cell types and origin. Although it has been shown that some signaling pathways are affected by LIPUS stimulation, this only partially illustrates how LIPUS works. Some questions remain regarding the mechanisms of LIPUS, including how LIPUS influences specific signaling pathways. There are newly emerging theoretical models which aim to further elucidate the bioeffects of LIPUS (131).

In conclusion, LIPUS, as a safe and convenient method, is promising for clinical use, further research is required to substantiate these findings.

\section{Acknowledgments}

Funding: None.

\section{Footnote}

Conflicts of Interest: All authors have completed the ICMJE uniform disclosure form (available at http://dx.doi. org/10.21037/qims-20-680). The authors have no conflicts of interest to declare.

Open Access Statement: This is an Open Access article distributed in accordance with the Creative Commons Attribution-NonCommercial-NoDerivs 4.0 International License (CC BY-NC-ND 4.0), which permits the noncommercial replication and distribution of the article with 
the strict proviso that no changes or edits are made and the original work is properly cited (including links to both the formal publication through the relevant DOI and the license). See: https://creativecommons.org/licenses/by-nc-nd/4.0/.

\section{References}

1. Zhang X, Hu B, Sun J, Li J, Liu S, Song J. Inhibitory Effect of Low-Intensity Pulsed Ultrasound on the Expression of Lipopolysaccharide-Induced Inflammatory Factors in U937 Cells. J Ultrasound Med 2017;36:2419-29.

2. Nakao J, Fujii Y, Kusuyama J, Bandow K, Kakimoto K, Ohnishi T, Matsuguchi T. Low-intensity pulsed ultrasound (LIPUS) inhibits LPS-induced inflammatory responses of osteoblasts through TLR4-MyD88 dissociation. Bone 2014;58:17-25.

3. Clark LF, Kodadek T. The Immune System and Neuroinflammation as Potential Sources of BloodBased Biomarkers for Alzheimer's Disease, Parkinson's Disease, and Huntington's Disease. ACS Chem Neurosci 2016;7:520-7.

4. Nagata K, Nakamura T, Fujihara S, Tanaka E. Ultrasound modulates the inflammatory response and promotes muscle regeneration in injured muscles. Ann Biomed Eng 2013;41:1095-105.

5. Polderman JA, Farhang-Razi V, Van Dieren S, Kranke P, DeVries JH, Hollmann MW, Preckel B, Hermanides J. Adverse side effects of dexamethasone in surgical patients. Cochrane Database Syst Rev 2018;11:CD011940.

6. Atkinson TJ, Fudin J. Nonsteroidal Antiinflammatory Drugs for Acute and Chronic Pain. Phys Med Rehabil Clin N Am 2020;31:219-31.

7. Xin Z, Lin G, Lei H, Lue TF, Guo Y. Clinical applications of low-intensity pulsed ultrasound and its potential role in urology. Transl Androl Urol 2016;5:255-66.

8. Tanaka E, Kuroda S, Horiuchi S, Tabata A, El-Bialy T. Low-intensity pulsed ultrasound in dentofacial tissue engineering. Ann Biomed Eng 2015;43:871-86.

9. Tang L, Li N, Jian W, Kang Y, Yin B, Sun S, Guo J, Sun L, Ta D. Low-intensity pulsed ultrasound prevents muscle atrophy induced by type 1 diabetes in rats. Skelet Muscle 2017;7:29.

10. Chiang PK, Yang FY. A potential treatment of low intensity pulsed ultrasound on cavernous nerve injury for erectile dysfunction. Med Hypotheses 2019;122:19-21.

11. Izadifar Z, Babyn P, Chapman D. Mechanical and
Biological Effects of Ultrasound: A Review of Present Knowledge. Ultrasound Med Biol 2017;43:1085-104.

12. Carina V, Costa V, Sartori M, Bellavia D, De Luca A, Raimondi L, Fini M, Giavaresi G. Adjuvant Biophysical Therapies in Osteosarcoma. Cancers (Basel) 2019;11:348.

13. Dalecki D. Mechanical bioeffects of ultrasound. Annu Rev Biomed Eng 2004;6:229-48.

14. Lin G, Reed-Maldonado AB, Lin M, Xin Z, Lue TF. Effects and Mechanisms of Low-Intensity Pulsed Ultrasound for Chronic Prostatitis and Chronic Pelvic Pain Syndrome. Int J Mol Sci 2016;17:1057.

15. Hu M, Wazir J, Ullah R, Wang W, Cui X, Tang M, Zhou $\mathrm{X}$. Phytotherapy and physical therapy in the management of chronic prostatitis-chronic pelvic pain syndrome. Int Urol Nephrol 2019;51:1081-8.

16. Holfeld J, Tepekoylu C, Kozaryn R, Urbschat A, Zacharowski K, Grimm M, Paulus P. Shockwave therapy differentially stimulates endothelial cells: implications on the control of inflammation via toll-Like receptor 3. Inflammation 2014;37:65-70.

17. Martelletti P, Barbanti P, Grazzi L, Pierangeli G, Rainero I, Geppetti P, Ambrosini A, Sarchielli P, Tassorelli C, Liebler E, de Tommaso M. Consistent effects of noninvasive vagus nerve stimulation (nVNS) for the acute treatment of migraine: additional findings from the randomized, sham-controlled, double-blind PRESTO trial. J Headache Pain 2018;19:101.

18. Chen YT, Yang CC, Sun CK, Chiang HJ, Chen YL, Sung PH, Zhen YY, Huang TH, Chang CL, Chen HH, Chang HW, Yip HK. Extracorporeal shock wave therapy ameliorates cyclophosphamide-induced rat acute interstitial cystitis though inhibiting inflammation and oxidative stress-in vitro and in vivo experiment studies. Am J Transl Res 2014;6:631-48.

19. Gardner AW, Parker DE, Montgomery PS. Changes in vascular and inflammatory biomarkers after exercise rehabilitation in patients with symptomatic peripheral artery disease. J Vasc Surg 2019;70:1280-90.

20. d'Agostino MC, Craig K, Tibalt E, Respizzi S. Shock wave as biological therapeutic tool: From mechanical stimulation to recovery and healing, through mechanotransduction. Int J Surg 2015;24:147-53.

21. ter Haar G. Therapeutic applications of ultrasound. Prog Biophys Mol Biol 2007;93:111-29.

22. Watson T. Ultrasound in contemporary physiotherapy practice. Ultrasonics 2008;48:321-9.

23. Hsieh YL, Chen H-Y, Yang C-C. Early Intervention with Therapeutic Low-Intensity Pulsed Ultrasound in Halting 
the Progression of Post-traumatic Osteoarthritis in a Rat Model. Ultrasound Med Biol 2018;44:2637-45.

24. Signori LU, Costa ST, Neto AF, Pizzolotto RM, Beck C, Sbruzzi G, Silva AM, Plentz RD. Haematological effect of pulsed ultrasound in acute muscular inflammation in rats. Physiotherapy 2011;97:163-9.

25. da Silva Junior EM, Mesquita-Ferrari RA, França CM, Andreo L, Bussadori SK, Fernandes KPS. Modulating effect of low intensity pulsed ultrasound on the phenotype of inflammatory cells. Biomed Pharmacother 2017;96:1147-53.

26. Montalti CS, Souza NV, Rodrigues NC, Fernandes KR, Toma RL, Renno AC. Effects of low-intensity pulsed ultrasound on injured skeletal muscle. Braz J Phys Ther 2013;17:343-50.

27. Zhang B, Chen H, Ouyang J, Xie Y, Chen L, Tan Q, Du X, Su N, Ni Z, Chen L. SQSTM1-dependent autophagic degradation of PKM2 inhibits the production of mature IL1B/IL-1 $\beta$ and contributes to LIPUS-mediated antiinflammatory effect. Autophagy 2020;16:1262-78.

28. Ogata T, Ito K, Shindo T, Hatanaka K, Eguchi K, Kurosawa R, Kagaya Y, Monma Y, Ichijo S, Taki H, Kanai H, Shimokawa H. Low-intensity pulsed ultrasound enhances angiogenesis and ameliorates contractile dysfunction of pressure-overloaded heart in mice. PLoS One 2017;12:e0185555.

29. Zheng C, Wu S-M, Lian H, Lin Y-Z, Zhuang R, Thapa S, Chen Q-Z, Chen Y-F, Lin J-F. Low-intensity pulsed ultrasound attenuates cardiac inflammation of CVB3induced viral myocarditis via regulation of caveolin-1 and MAPK pathways. J Cell Mol Med 2019;23:1963-75.

30. Shindo T, Ito K, Ogata T, Hatanaka K, Kurosawa R, Eguchi K, Kagaya Y, Hanawa K, Aizawa K, Shiroto T, Kasukabe S, Miyata S, Taki H, Hasegawa H, Kanai H, Shimokawa H. Low-Intensity Pulsed Ultrasound Enhances Angiogenesis and Ameliorates Left Ventricular Dysfunction in a Mouse Model of Acute Myocardial Infarction. Arterioscler Thromb Vasc Biol 2016;36:1220-9.

31. Li J, Zhang Q, Ren C, Wu X, Zhang Y, Bai X, Lin Y, Li M, Fu J, Kopylov P, Wang S, Yu T, Wang N, Xu C, Zhang Y, Yang B. Low-Intensity Pulsed Ultrasound Prevents the Oxidative Stress Induced Endothelial-Mesenchymal Transition in Human Aortic Endothelial Cells. Cell Physiol Biochem 2018;45:1350-65.

32. Li X, Li X, Lin J, Sun X, Ding Q. Exosomes Derived From Low-Intensity Pulsed Ultrasound-Treated Dendritic Cells Suppress Tumor Necrosis Factor-
Induced Endothelial Inflammation. J Ultrasound Med 2019;38:2081-91.

33. Wang S, Hu Z, Wang X, Gu C, Gao Z, Cao W, Zheng J. 5-Aminolevulinic acid-mediated sonodynamic therapy reverses macrophage and dendritic cell passivity in murine melanoma xenografts. Ultrasound Med Biol 2014;40:2125-33.

34. Tang CH, Yang RS, Huang TH, Lu DY, Chuang WJ, Huang TF, Fu WM. Ultrasound stimulates cyclooxygenase-2 expression and increases bone formation through integrin, focal adhesion kinase, phosphatidylinositol 3-kinase, and Akt pathway in osteoblasts. Mol Pharmacol 2006;69:2047-57.

35. Bandow K, Nishikawa Y, Ohnishi T, Kakimoto K, Soejima K, Iwabuchi S, Kuroe K, Matsuguchi T. Lowintensity pulsed ultrasound (LIPUS) induces RANKL, MCP-1, and MIP-1beta expression in osteoblasts through the angiotensin II type 1 receptor. J Cell Physiol 2007;211:392-8.

36. Feres MFN, Kucharski C, Diar-Bakirly S, El-Bialy T. Effect of low-intensity pulsed ultrasound on the activity of osteoclasts: An in vitro study. Arch Oral Biol 2016;70:73-8.

37. Uddin SM, Richbourgh B, Ding Y, Hettinghouse A, Komatsu DE, Qin YX, Liu CJ. Chondro-protective effects of low intensity pulsed ultrasound. Osteoarthritis Cartilage 2016;24:1989-98.

38. Jia L, Chen J, Wang Y, Zhang Y, Chen W. Focused Lowintensity Pulsed Ultrasound Affects Extracellular Matrix Degradation via Decreasing Chondrocyte Apoptosis and Inflammatory Mediators in a Surgically Induced Osteoarthritic Rabbit Model. Ultrasound Med Biol 2016;42:208-19.

39. Nakamura T, Fujihara S, Katsura T, Yamamoto K, Inubushi T, Tanimoto K, Tanaka E. Effects of lowintensity pulsed ultrasound on the expression and activity of hyaluronan synthase and hyaluronidase in IL-1beta-stimulated synovial cells. Ann Biomed Eng 2010;38:3363-70.

40. Nakamura T, Fujihara S, Yamamoto-Nagata K, Katsura T, Inubushi T, Tanaka E. Low-intensity pulsed ultrasound reduces the inflammatory activity of synovitis. Ann Biomed Eng 2011;39:2964-71.

41. Sato M, Nagata K, Kuroda S, Horiuchi S, Nakamura T, Karima M, Inubushi T, Tanaka E. Low-intensity pulsed ultrasound activates integrin-mediated mechanotransduction pathway in synovial cells. Ann Biomed Eng 2014;42:2156-63. 
42. Chen SF, Su WS, Wu CH, Lan TH, Yang FY. Transcranial Ultrasound Stimulation Improves LongTerm Functional Outcomes and Protects Against Brain Damage in Traumatic Brain Injury. Mol Neurobiol 2018;55:7079-89.

43. Chen TT, Lan TH, Yang FY. Low-Intensity Pulsed Ultrasound Attenuates LPS-Induced Neuroinflammation and Memory Impairment by Modulation of TLR4/NFkappaB Signaling and CREB/BDNF Expression. Cereb Cortex 2019;29:1430-8.

44. Eming SA, Wynn TA, Martin P. Inflammation and metabolism in tissue repair and regeneration. Science 2017;356:1026-30.

45. Rai MF, Duan X, Quirk JD, Holguin N, Schmidt EJ, Chinzei N, Silva MJ, Sandell LJ. Post-Traumatic Osteoarthritis in Mice Following Mechanical Injury to the Synovial Joint. Sci Rep 2017;7:45223.

46. Shiratsuchi H, Basson MD. Activation of $\mathrm{p} 38$ MAPKalpha by extracellular pressure mediates the stimulation of macrophage phagocytosis by pressure. Am J Physiol Cell Physiol 2005;288:C1083-93.

47. Shiratsuchi H, Basson MD. Akt2, but not Akt1 or Akt3 mediates pressure-stimulated serum-opsonized latex bead phagocytosis through activating mTOR and p70 S6 kinase. J Cell Biochem 2007;102:353-67.

48. Shiratsuchi H, Basson MD. Extracellular pressure stimulates macrophage phagocytosis by inhibiting a pathway involving FAK and ERK. Am J Physiol Cell Physiol 2004;286:C1358-66.

49. Wynn TA, Vannella KM. Macrophages in Tissue Repair, Regeneration, and Fibrosis. Immunity 2016;44:450-62.

50. Van Krieken R, Krepinsky JC. Caveolin-1 in the Pathogenesis of Diabetic Nephropathy: Potential Therapeutic Target? Curr Diab Rep 2017;17:19.

51. Srivastav RK, Ansari TM, Prasad M, Vishwakarma VK, Bagga P, Ahsan F. Caveolins; An Assailant or An Ally of Various Cellular Disorders. Drug Res (Stuttg) 2019;69:419-27.

52. de Almeida CJG. Caveolin-1 and Caveolin-2 Can Be Antagonistic Partners in Inflammation and Beyond. Front Immunol 2017;8:1530.

53. Nwosu ZC, Ebert MP, Dooley S, Meyer C. Caveolin-1 in the regulation of cell metabolism: a cancer perspective. Mol Cancer 2016;15:71.

54. Chistiakov DA, Orekhov AN, Bobryshev YV. Effects of shear stress on endothelial cells: go with the flow. Acta Physiol (Oxf) 2017;219:382-408.

55. Abe Y, Ito K, Hao K, Shindo T, Ogata T, Kagaya
Y, Kurosawa R, Nishimiya K, Satoh K, Miyata S, Kawakami K, Shimokawa H. Extracorporeal low-energy shock-wave therapy exerts anti-inflammatory effects in a rat model of acute myocardial infarction. Circulation journal: official journal of the Japanese Circulation Society 2014;78:2915-25.

56. Gadomski BC, McGilvray KC, Easley JT, Palmer RH, Jiao J, Li X, Qin YX, Puttlitz CM. An investigation of shock wave therapy and low-intensity pulsed ultrasound on fracture healing under reduced loading conditions in an ovine model. J Orthop Res 2018;36:921-9.

57. Chung E, Lee J, Liu CC, Taniguchi H, Zhou HL, Park HJ. Clinical Practice Guideline Recommendation on the Use of Low Intensity Extracorporeal Shock Wave Therapy and Low Intensity Pulsed Ultrasound Shock Wave Therapy to Treat Erectile Dysfunction: The AsiaPacific Society for Sexual Medicine Position Statement. World J Mens Health 2020. [Epub ahead of print]. doi: 10.5534/wjmh.200077.

58. Yılmaz V, Karada Ö, Dandino lu T, Umay E, Çakçı A, Tan AK. Efficacy of extracorporeal shockwave therapy and low-intensity pulsed ultrasound in a rat knee osteoarthritis model: A randomized controlled trial. Eur J Rheumatol 2017;4:104-8.

59. Albanesi C, De Pità O, Girolomoni G. Resident skin cells in psoriasis: a special look at the pathogenetic functions of keratinocytes. Clin Dermatol 2007;25:581-8.

60. Albanesi C, Scarponi C, Giustizieri M, Girolomoni G. Keratinocytes in inflammatory skin diseases. Curr Drug Targets Inflamm Allergy 2005;4:329-34.

61. Alexander M, Hu R, Runtsch MC, Kagele DA, Mosbruger TL, Tolmachova T, Seabra MC, Round JL, Ward DM, O'Connell RM. Exosome-delivered microRNAs modulate the inflammatory response to endotoxin. Nat Commun 2015;6:7321.

62. Liu Z, Tao B, Fan S, Pu Y, Xia H, Xu L. MicroRNA-145 Protects against Myocardial Ischemia Reperfusion Injury via CaMKII-Mediated Antiapoptotic and AntiInflammatory Pathways. Oxid Med Cell Longev 2019;2019:8948657.

63. Hui Y, Yin Y. MicroRNA-145 attenuates high glucoseinduced oxidative stress and inflammation in retinal endothelial cells through regulating TLR4/NF-kappaB signaling. Life Sci 2018;207:212-8.

64. Buzas EI, György B, Nagy G, Falus A, Gay S. Emerging role of extracellular vesicles in inflammatory diseases. Nat Rev Rheumatol 2014;10:356-64.

65. Boulanger CM, Loyer X, Rautou PE, Amabile N. 
Extracellular vesicles in coronary artery disease. Nat Rev Cardiol 2017;14:259-72.

66. Scarponi C, Nasorri F, Pavani F, Madonna S, Sestito R, Simonacci M, De Pita O, Cavani A, Albanesi C. Low-frequency low-intensity ultrasounds do not influence the survival and immune functions of cultured keratinocytes and dendritic cells. J Biomed Biotechnol 2009;2009:193260.

67. Yang Q, Nanayakkara GK, Drummer C, Sun Y, Johnson C, Cueto R, Fu H, Shao Y, Wang L, Yang WY, Tang P, Liu LW, Ge S, Zhou XD, Khan M, Wang H, Yang X. Low-Intensity Ultrasound-Induced Anti-inflammatory Effects Are Mediated by Several New Mechanisms Including Gene Induction, Immunosuppressor Cell Promotion, and Enhancement of Exosome Biogenesis and Docking. Front Physiol 2017;8:818.

68. Song J, Li N, Xia Y, Gao Z, Zou SF, Yan YH, Li SH, Wang Y, Meng YK, Yang JX, Kang TG. Arctigenin Confers Neuroprotection Against Mechanical Trauma Injury in Human Neuroblastoma SH-SY5Y Cells by Regulating miRNA-16 and miRNA-199a Expression to Alleviate Inflammation. J Mol Neurosci 2016;60:115-29.

69. Caescu CI, Guo X, Tesfa L, Bhagat TD, Verma A, Zheng D, Stanley ER. Colony stimulating factor-1 receptor signaling networks inhibit mouse macrophage inflammatory responses by induction of microRNA- 21 . Blood 2015;125:e1-13.

70. Hurwitz AA, Watkins SK. Immune suppression in the tumor microenvironment: a role for dendritic cellmediated tolerization of $\mathrm{T}$ cells. Cancer immunology, immunotherapy: Cancer Immunol Immunother 2012;61:289-93.

71. Kon T, Cho TJ, Aizawa T, Yamazaki M, Nooh N, Graves D, Gerstenfeld LC, Einhorn TA. Expression of osteoprotegerin, receptor activator of NF-kappaB ligand (osteoprotegerin ligand) and related proinflammatory cytokines during fracture healing. J Bone Miner Res 2001;16:1004-14.

72. Adamopoulos IE. Inflammation in bone physiology and pathology. Curr Opin Rheumatol 2018;30:59-64.

73. Loi F, Córdova LA, Pajarinen J, Lin T-h, Yao Z, Goodman SB. Inflammation, fracture and bone repair. Bone 2016;86:119-30.

74. Horwood NJ. Macrophage Polarization and Bone Formation: A review. Clin Rev Allergy Immunol 2016;51:79-86.

75. Gibon E, Lu L, Goodman SB. Aging, inflammation, stem cells, and bone healing. Stem Cell Res Ther 2016;7:44 .
76. Kokubu T, Matsui N, Fujioka H, Tsunoda M, Mizuno $\mathrm{K}$. Low intensity pulsed ultrasound exposure increases prostaglandin E2 production via the induction of cyclooxygenase- 2 mRNA in mouse osteoblasts. Biochem Biophys Res Commun 1999;256:284-7.

77. Ren L, Yang Z, Song J, Wang Z, Deng F, Li W. Involvement of p38 MAPK pathway in low intensity pulsed ultrasound induced osteogenic differentiation of human periodontal ligament cells. Ultrasonics 2013;53:686-90.

78. Joos H, Wildner A, Hogrefe C, Reichel H, Brenner RE. Interleukin-1 beta and tumor necrosis factor alpha inhibit migration activity of chondrogenic progenitor cells from non-fibrillated osteoarthritic cartilage. Arthritis Res Ther 2013;15:R119.

79. Goldring MB. Osteoarthritis and cartilage: the role of cytokines. Curr Rheumatol Rep 2000;2:459-65.

80. Wang T, He C. Pro-inflammatory cytokines: The link between obesity and osteoarthritis. Cytokine Growth Factor Rev 2018;44:38-50.

81. Lammi MJ. Current perspectives on cartilage and chondrocyte mechanobiology. Biorheology 2004;41:593-6.

82. Sanchez-Adams J, Leddy HA, McNulty AL, O'Conor CJ, Guilak F. The mechanobiology of articular cartilage: bearing the burden of osteoarthritis. Curr Rheumatol Rep 2014;16:451.

83. Sahu N, Viljoen HJ, Subramanian A. Continuous lowintensity ultrasound attenuates IL-6 and TNFalphainduced catabolic effects and repairs chondral fissures in bovine osteochondral explants. BMC Musculoskelet Disord 2019;20:193.

84. Cruz JM, Hauck M, Cardoso Pereira AP, Moraes MB, Martins CN, da Silva Paulitsch F, Plentz RD, Peres W, Vargas da Silva AM, Signori LU. Effects of Different Therapeutic Ultrasound Waveforms on Endothelial Function in Healthy Volunteers: A Randomized Clinical Trial. Ultrasound Med Biol 2016;42:471-80.

85. Rubira APFA, Rubira MC, Rubira LA, Comachio J, Magalhães MO, Marques AP. Comparison of the effects of low-level laser and pulsed and continuous ultrasound on pain and physical disability in chronic non-specific low back pain: a randomized controlled clinical trial. Adv Rheumatol 2019;59:57.

86. Ilter L, Dilek B, Batmaz I, Ulu MA, Sariyildiz MA, Nas K, Cevik R. Efficacy of Pulsed and Continuous Therapeutic Ultrasound in Myofascial Pain Syndrome: A Randomized Controlled Study. Am J Phys Med Rehabil 2015;94:547-54. 
87. Alfredo PP, Junior WS, Casarotto RA. Efficacy of continuous and pulsed therapeutic ultrasound combined with exercises for knee osteoarthritis: a randomized controlled trial. Clin Rehabil 2020;34:480-90.

88. Baker KG, Robertson VJ, Duck FA. A review of therapeutic ultrasound: biophysical effects. Phys Ther 2001;81:1351-8.

89. Huebner JL, Kraus VB. Assessment of the utility of biomarkers of osteoarthritis in the guinea pig. Osteoarthritis Cartilage 2006;14:923-30.

90. Fernandes JC, Martel-Pelletier J, Pelletier JP. The role of cytokines in osteoarthritis pathophysiology. Biorheology 2002;39:237-46.

91. Falconer J, Murphy AN, Young SP, Clark AR, Tiziani S, Guma M, Buckley CD. Review: Synovial Cell Metabolism and Chronic Inflammation in Rheumatoid Arthritis. Arthritis Rheumatol 2018;70:984-99.

92. Skaper SD, Facci L, Zusso M, Giusti P. Neuroinflammation, Mast Cells, and Glia: Dangerous Liaisons. Neuroscientist 2017;23:478-98.

93. Yang QQ, Zhou JW. Neuroinflammation in the central nervous system: Symphony of glial cells. Glia 2019;67:1017-35.

94. Ransohoff RM. How neuroinflammation contributes to neurodegeneration. Science 2016;353:777-83.

95. Tyler WJ, Lani SW, Hwang GM. Ultrasonic modulation of neural circuit activity. Curr Opin Neurobiol 2018;50:222-31.

96. Leinenga G, Langton C, Nisbet R, Götz J. Ultrasound treatment of neurological diseases--current and emerging applications. Nat Rev Neurol 2016;12:161-74.

97. Li X, Yang H, Yan J, Wang X, Li X, Yuan Y. LowIntensity Pulsed Ultrasound Stimulation Modulates the Nonlinear Dynamics of Local Field Potentials in Temporal Lobe Epilepsy. Front Neurosci 2019;13:287.

98. Fomenko A, Neudorfer C, Dallapiazza RF, Kalia SK, Lozano AM. Low-intensity ultrasound neuromodulation: An overview of mechanisms and emerging human applications. Brain Stimul 2018;11:1209-17.

99. Clark LF, Kodadek T. The Immune System and Neuroinflammation as Potential Sources of BloodBased Biomarkers for Alzheimer's Disease, Parkinson's Disease, and Huntington's Disease. ACS Chem Neurosci 2016;7:520-7.

100.McKenzie JA, Spielman LJ, Pointer CB, Lowry JR, Bajwa E, Lee CW, Klegeris A. Neuroinflammation as a Common Mechanism Associated with the Modifiable Risk Factors for Alzheimer's and Parkinson's Diseases.
Curr Aging Sci 2017;10:158-76.

101.Leite JP, Peixoto-Santos JE. Glia and extracellular matrix molecules: What are their importance for the electrographic and MRI changes in the epileptogenic zone? Epilepsy Behav 2019:106542.

102.Peng DY, Reed-Maldonado AB, Lin GT, Xia SJ, Lue TF. Low-intensity pulsed ultrasound for regenerating peripheral nerves: potential for penile nerve. Asian J Androl 2020;22:335-41.

103.Hausner T, Nogradi A. The use of shock waves in peripheral nerve regeneration: new perspectives? Int Rev Neurobiol 2013;109:85-98.

104.Busse JW, Kaur J, Mollon B, Bhandari M, Tornetta P, 3rd, Schünemann HJ, Guyatt GH. Low intensity pulsed ultrasonography for fractures: systematic review of randomised controlled trials. BMJ 2009;338:b351.

105.Ng CF, Yee CH, Teoh JYC, Lau B, Leung SCH, Wong CYP, Wong KT, Chu WCW, Yuen J. Effect of Stepwise Voltage Escalation on Treatment Outcomes following Extracorporeal Shock Wave Lithotripsy of Renal Calculi: A Prospective Randomized Study. J Urol 2019;202:986-93.

106. Samuels JA, Weingarten MS, Margolis DJ, Zubkov L, Sunny Y, Bawiec CR, Conover D, Lewin PA. Lowfrequency $(<100 \mathrm{kHz})$, low-intensity $(<100 \mathrm{~mW} / \mathrm{cm}(2))$ ultrasound to treat venous ulcers: a human study and in vitro experiments. J Acoust Soc Am 2013;134:1541-7.

107.Bajpai A, Nadkarni S, Neidrauer M, Weingarten MS, Lewin PA, Spiller KL. Effects of Non-thermal, Noncavitational Ultrasound Exposure on Human Diabetic Ulcer Healing and Inflammatory Gene Expression in a Pilot Study. Ultrasound Med Biol 2018;44:2043-9.

108.Cui W, Li H, Guan R, Li M, Yang B, Xu Z, Lin M, Tian L, Zhang X, Li B, Liu W, Dong Z, Wang Z, Zheng T, Zhang W, Lin G, Guo Y, Xin Z. Efficacy and safety of novel low-intensity pulsed ultrasound (LIPUS) in treating mild to moderate erectile dysfunction: a multicenter, randomized, double-blind, sham-controlled clinical study. Transl Androl Urol 2019;8:307-19.

109.Hauck M, Noronha Martins C, Borges Moraes M, Aikawa P, da Silva Paulitsch F, Mea Plentz RD, Teixeira da Costa S, Vargas da Silva AM, Signori LU. Comparison of the effects of $1 \mathrm{MHz}$ and $3 \mathrm{MHz}$ therapeutic ultrasound on endothelium-dependent vasodilation of humans: a randomised clinical trial. Physiotherapy 2019;105:120-5.

110.Feizabadi N, Sarrafzadeh J, Fathali M, VasaghiGharamaleki B, Dadgoo M, Kardan-Yamchi J, Kazemian H, Hesam-Shariati S, Feizabadi MM. The pulsed ultrasound strategy effectively decreases the S. aureus 
population of chronic rhinosinusitis patients. BMC Res Notes 2019;12:576.

111.Kim ED, Won YH, Park SH, Seo JH, Kim DS, Ko MH, Kim GW. Efficacy and Safety of a Stimulator Using Low-Intensity Pulsed Ultrasound Combined with Transcutaneous Electrical Nerve Stimulation in Patients with Painful Knee Osteoarthritis. Pain Res Manag 2019;2019:7964897.

112.Raza H, Major P, Dederich D, El-Bialy T. Effect of low-intensity pulsed ultrasound on orthodontically induced root resorption caused by torque: A prospective, double-blind, controlled clinical trial. Angle Orthod 2016;86:550-7.

113. Tsukada M, Takiuchi T, Watanabe K. Low-Intensity Pulsed Ultrasound for Early-Stage Lumbar Spondylolysis in Young Athletes. Clin J Sport Med 2019;29:262-6.

114.Karosi T, Sziklai I, Csomor P. Low-frequency ultrasound for biofilm disruption in chronic rhinosinusitis with nasal polyposis: in vitro pilot study. Laryngoscope 2013;123:17-23.

115.Bartley J, Ansari NN, Naghdi S. Therapeutic ultrasound as a treatment modality for chronic rhinosinusitis. Curr Infect Dis Rep 2014;16:398.

116. Malik A, Morya RK, Saha S, Singh PK, Bhadada SK, Rana SV. Oxidative stress and inflammatory markers in type 2 diabetic patients. Eur J Clin Invest 2020;50:e13238.

117. Chen Y, Jiao N, Jiang M, Liu L, Zhu Y, Wu H, Chen J, Fu Y, Du Q, Xu H, Sun J. Loganin alleviates testicular damage and germ cell apoptosis induced by AGEs upon diabetes mellitus by suppressing the RAGE/p38MAPK/ NF- B pathway. J Cell Mol Med 2020;24:6083-95.

118.Joung KH, Kim JM, Choung S, Lee JH, Kim HJ, Ku BJ. Association between IL-1beta and cardiovascular disease risk in patients with newly diagnosed, drug-naïve type 2 diabetes mellitus: a cross-sectional study. Ann Transl Med 2020;8:225.

119.Xu T, Zhao K, Guo X, Tu J, Zhang D, Sun W, Kong $\mathrm{X}$. Low-intensity pulsed ultrasound inhibits adipogenic differentiation via HDAC1 signalling in rat visceral preadipocytes. Adipocyte 2019;8:292-303.

120.Nishida T, Nagao Y, Hashitani S, Yamanaka N, Takigawa M, Kubota S. Suppression of adipocyte differentiation by low-intensity pulsed ultrasound via inhibition of insulin signaling and promotion of CCN family protein 2. J Cell Biochem 2020. [Epub ahead of print]. doi: 10.1002/ jcb. 29680.

121.Kusuyama J, Bandow K, Shamoto M, Kakimoto
K, Ohnishi T, Matsuguchi T. Low intensity pulsed ultrasound (LIPUS) influences the multilineage differentiation of mesenchymal stem and progenitor cell lines through ROCK-Cot/Tpl2-MEK-ERK signaling pathway. J Biol Chem 2014;289:10330-44.

122.Ling L, Wei T, He L, Wang Y, Wang Y, Feng X, Zhang W, Xiong Z. Low-intensity pulsed ultrasound activates ERK1/2 and PI3K-Akt signalling pathways and promotes the proliferation of human amnion-derived mesenchymal stem cells. Cell Prolif 2017;50:e12383.

123.Ling L, Feng X, Wei T, Wang Y, Wang Y, Zhang W, He L, Wang Z, Zeng Q, Xiong Z. Effects of lowintensity pulsed ultrasound (LIPUS)-pretreated human amnion-derived mesenchymal stem cell (hAD-MSC) transplantation on primary ovarian insufficiency in rats. Stem Cell Res Ther 2017;8:283.

124.Xia B, Chen G, Zou Y, Yang L, Pan J, Lv Y. Lowintensity pulsed ultrasound combination with induced pluripotent stem cells-derived neural crest stem cells and growth differentiation factor 5 promotes sciatic nerve regeneration and functional recovery. J Tissue Eng Regen Med 2019;13:625-36.

125.Lv Y, Nan P, Chen G, Sha Y, Xia B, Yang L. In vivo repair of rat transected sciatic nerve by low-intensity pulsed ultrasound and induced pluripotent stem cells-derived neural crest stem cells. Biotechnol Lett 2015;37:2497-506.

126.Tsai CL, Chang WH, Liu TK. Preliminary studies of duration and intensity of ultrasonic treatments on fracture repair. Chin J Physiol 1992;35:21-6.

127.Schumann D, Kujat R, Zellner J, Angele MK, Nerlich M, Mayr E, Angele P. Treatment of human mesenchymal stem cells with pulsed low intensity ultrasound enhances the chondrogenic phenotype in vitro. Biorheology 2006;43:431-43.

128. Busse JW, Bhandari M, Einhorn TA, Schemitsch E, Heckman JD, Tornetta P, 3rd, Leung KS, Heels-Ansdell D, Makosso-Kallyth S, Della Rocca GJ, Jones CB, Guyatt GH. Re-evaluation of low intensity pulsed ultrasound in treatment of tibial fractures (TRUST): randomized clinical trial. BMJ 2016;355:15351.

129.Simpson AH, Keenan G, Nayagam S, Atkins RM, Marsh D, Clement ND. Low-intensity pulsed ultrasound does not influence bone healing by distraction osteogenesis: a multicentre double-blind randomised control trial. Bone Joint J 2017;99-B:494-502.

130.'Tarride JE, Hopkins RB, Blackhouse G, Burke N, Bhandari M, Johal H, Guyatt GH, Busse JW. Low- 
intensity pulsed ultrasound for treatment of tibial

fractures: an economic evaluation of the TRUST study.

Bone Joint J 2017;99-B:1526-32.

131. Miller AD, Chama A, Louw TM, Subramanian A,
Viljoen HJ. Frequency sensitive mechanism in lowintensity ultrasound enhanced bioeffects. PLoS One 2017;12:e0181717.

Cite this article as: $\mathrm{Xu} \mathrm{M,} \mathrm{Wang} \mathrm{L,} \mathrm{Wu} \mathrm{S,} \mathrm{Dong} \mathrm{Y,} \mathrm{Chen} \mathrm{X,}$ Wang S, Li X, Zou C. Review on experimental study and clinical application of low-intensity pulsed ultrasound in inflammation. Quant Imaging Med Surg 2021;11(1):443-462. doi: 10.21037/qims-20-680 